\title{
HIGH PRESSURE THERMODYNAMICS OF MIXTURES
}

\author{
G. M. SCHNEIDER \\ University of Bochum/GFR, Institute of Physical Chemistry, German Federal Republic
}

\begin{abstract}
In the present survey some important trends in the high pressure thermodynamics of fluid mixtures of non-electrolytes are reviewed.

First the pressure dependence of excess functions such as the excess Gibbs energy $G^{E}$, the excess enthalpy $H^{E}$, the excess entropy $S^{E}$ and the excess heat capacity $C_{p}{ }^{E}$ is discussed. It can be obtained from the knowledge of the excess volume $V^{E}$ as a function of pressure, temperature and composition. Experimental results demonstrate that the variations of $V^{E}$ as a function of pressure and temperature can be important and comparable to those of the molar volumes themselves. A detailed discussion shows that further progress in this field depends on the development of an accurate equation of state for mixtures.

Since furthermore direct calorimetric measurements are practically completely lacking at high pressures most thermodynamic informations have to be deduced up to now from high pressure phase equilibria and critical phenomena where our knowledge is much better. The pressure dependence and critical phenomena of liquid-gas, liquid-liquid and gas-gas equilibria will be shortly reviewed. Mainly binary systems will be treated but phase separation phenomena in some ternary and multicomponent systems will be equally considered. Recent results concerning the rate of phase separation will be additionally presented.

New developments during recent years have shown that the limits between liquid-gas, liquid-liquid and gas-gas equilibria are not well defined and that continuous transitions occur. This continuity will be demonstrated for binary mixtures of hydrocarbons with carbon dioxide and methane and for some inert gas systems.

The significance of high pressure phase equilibria in fluid mixtures for practical applications is shortly discussed, e.g. for high pressure extractions, supercritical fluid chromatography and for some other high pressure techniques and processes.

Methods for the calculation of fluid phase equilibria in mixtures under high pressure are reviewed. They start from equations of state or from theories of mixtures using sometimes sophisticated mixing rules for the parameters. Some results are presented and compared with experimental data.

Finally a characteristic example for the pressure dependence of chemical equilibria in liquid solutions is considered and the standard value of the reaction volume $\Delta V^{\theta}$ is determined from measurements of the equilibrium constant $K$ as a function of pressure at constant temperature. It is shown how standard values of the reaction enthalpy $\Delta H^{\theta}$ can be obtained from temperature jump experiments in such solutions at high pressure.
\end{abstract}

\section{INTRODUCTION}

The thermodynamics of mixtures is one of the most important fields of thermodynamics. It has been of fundamental interest to chemists for a long time especially with respect to the thermodynamic and theoretical description of mixtures and solutions, to chemical equilibria and to some important methods of separation. An enormous amount of experimental and theoretical work has already been done in the thermodynamic investigation of mixtures but up to now the pressure variable has been widely neglected although in the first decades of our century very promising efforts had been done especially by the Dutch school.

Thus the high pressure thermodynamics of mixtures is still in a developing state whereas much more research activities have already been dedicated to the high pressure properties of pure compounds, the most recent literature being regularly reported in the Bibliography of High Pressure Research ${ }^{1}$ (for literature up to 1969, see Ref. 2).

In the present review some important trends in the high pressure thermodynamics of fluid mixtures of nonelectrolytes will be discussed; the accent will be on the discussion of some special high pressure effects that might be of interest to thermodynamicists working in other fields. Polar and ionic fluids at high pressures and temperatures have been treated by Franck ${ }^{3}$ at the Third International Conference on Chemical Thermodynamics. Electrolyte solutions under pressure have been recently reviewed by Hamann ${ }^{4}$ and critical phenomena in electrolyte solutions by Horvath. ${ }^{113}$ Throughout this paper the pressure unit bar will be used $\left(1 \mathrm{bar}=10^{5} \mathrm{~Pa}=0.1 \mathrm{MPa}\right.$; $1 \mathrm{kbar}=10^{3}$ bar; $1 \mathrm{Mbar}=10^{6} \mathrm{bar}$ ).
In Fig. 1 some pressures that are important in nature and chemical industry are summarized, making use of a similar compilation by Pilz. ${ }^{5}$ On the left hand side some pressures relevant in nature are given in logarithmic scale: critical pressures are between 2.3 bar for helium and approximately $1.5 \mathrm{kbar}$ for mercury; the deepest ocean corresponds to approximately $1 \mathrm{kbar}$ and the center of the earth to approximately $4 \mathrm{Mbar}$.

More interesting for chemists is the right hand column in Fig. 1 where some high pressure processes and techniques are compiled that are relevant to the European chemical industry. Between 100 and 1000 bar we have high pressure liquid chromatography (LC) and supercritical fluid chromatography (SFC), crystal growth, some hydrogenations; the syntheses of ammonia, of methanol, of some organic compounds by oxo synthesis and of acetic acid; and additionally some polymerisations. The fabrication of polyethylene occurs between 1.5 and $3 \mathrm{kbar}$ and the synthesis of diamond at approximately $50 \mathrm{kbar}$. For all these methods and processes the high pressure thermodynamics of mixtures is of fundamental importance. Hydrostatic extrusion, high pressure densification and sintering will become more and more interesting for material research. Explosive welding and plating are indispensable techniques for the fabrication of chemical reactors and tubing.

\section{EXCESS FUNCTIONS AND EQUATION OF STATE OF MIXTURES}

For the thermodynamic description of mixtures (especially of liquid mixtures) excess functions are often 


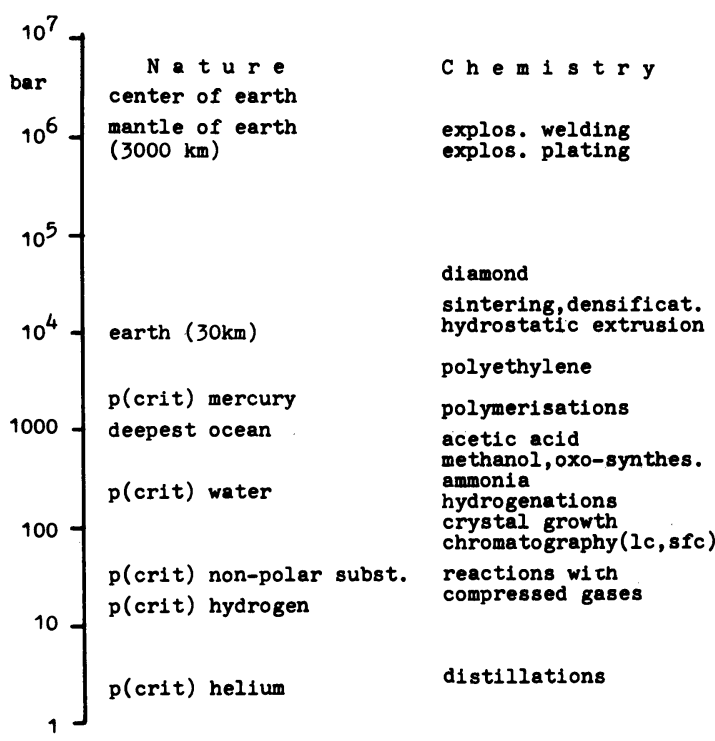

Fig. 1. Pressure scale in nature and chemistry (according to a similar compilation by $\mathrm{Pilz}^{5}$ ).

used. ${ }^{6-8}$ A molar excess function $Z_{m}{ }^{E}$ is defined as the difference of the molar function $Z_{m}$ between a real and an ideal mixture at the same values of temperature $T$, total pressure $p$ and mole fraction $x_{i}$ of all constituents $i$, where $Z=G, H, S, V, C_{p}$ etc.

$$
X_{m}{ }^{E}=Z_{m}(\text { real })-Z_{m}(\text { ideal }) \text { for } p, T, x_{i}=\text { const. }
$$

It can be easily shown that the following relations hold for the pressure dependence of the excess functions $s^{6-8}$

$$
\begin{aligned}
& \left(\frac{\partial G_{m}^{E}}{\partial p}\right)_{T, x_{i}}=V_{m}^{E} \\
& \left(\frac{\partial H_{m}^{E}}{\partial p}\right)_{T, x_{i}}=V_{m}^{E}-T\left(\frac{\partial V_{m}^{E}}{\partial T}\right)_{p, x_{i}} \\
& \left(\frac{\partial S_{m}^{E}}{\partial p}\right)_{T, x_{i}}=-\left(\frac{\partial V_{m}^{E}}{\partial T}\right)_{p, x_{i}} \\
& \left(\frac{\partial C_{p m}^{E}}{\partial p}\right)_{T, x_{i}}=-\left(\frac{\partial^{2} V_{m}^{E}}{\partial T^{2}}\right)_{p, x_{i}}
\end{aligned}
$$

It follows from the right hand sides of the relations (2-5) that the pressure derivatives of all molar excess functions are completely described by the molar excess volume $V_{m}{ }^{E}$ as a function of temperature, pressure and mole fractions. From this the excess functions themselves can be obtained by integration e.g. the molar excess Gibbs energy by

$$
G_{m}{ }^{E}(p)-G_{m}{ }^{E}\left(p^{0}\right)=\int_{p^{0}}^{p} V_{m}^{E} \mathrm{~d} p \text { for } T, x_{i}=\text { const. }
$$

where $G_{m}{ }^{E}\left(p^{0}\right)$ is the value of the molar excess Gibbs energy at the reference pressure $p^{0}$.

Thus the problem of thermodynamics of mixtures reduces to the knowledge of the molar excess volume $V_{m}{ }^{E}$ as a function of pressure, temperature and composition or, more generally, to the knowledge of an equation of state for mixtures at high pressure.

Such an equation of state can be based on the excess volume $V_{m}{ }^{E}$ or on the molar volume $V_{m}$ of the mixture itself where

$$
V_{m}(\text { real })=V_{m}(\text { ideal })+V_{m}^{E}=\sum_{i} x_{i} \cdot V_{m i}^{*}+V_{m}^{E} .
$$

According to eqn (7) $V_{m}$ is made up of two terms: (1) of the ideal term taking account of the molar volumes $V_{m i}^{*}$ of the pure components $i$ and (2) of the molar excess volume $V_{m}{ }^{E}$ as a correction term.

For pure liquids already many $p V T$ measurements have been undertaken up to quite high pressures. The data have been correlated with the well-known equations of state of Tait, ${ }^{9}$ Hudleston, ${ }^{10}$ Hayward, ${ }^{11}$ Chaudhuri, ${ }^{12}$ Witt, ${ }^{13}$ and others. Several authors have shown recently that among the two-parameter equations the old Tait equation does astonishingly well. ${ }^{2,7,14,15} \mathrm{Up}$ to now very few measurements, however, exist on mixtures and here the equations cited are not yet well tested especially with respect to the mixing rules for the parameters. The volumes of coexisting phases at high pressures have been measured by Tsiklis et al. ${ }^{114}$

The situation is not at all good for the molar excess volumes $V_{m}^{E}$ (for a review see ${ }^{16}$; for references see $\left.{ }^{16,110,111}\right)$, Up to now only very few $V_{m}{ }^{E}$ data exist at high pressures e.g. by Hamann and Smyth, ${ }^{17}$ Engels, ${ }^{18-20}$ Lamb and Hunt, ${ }^{21}$ Korpela, ${ }^{22}$ and Götze. ${ }^{23,24} V_{m}{ }^{E}$ data can be obtained from very accurate $p V T$ data measured separately on different mixtures and on all pure components or more precisely from measuring $V_{m}{ }^{E}$ directly as a function of pressure, temperature and composition. In Figs. 2 and 3 some results of Götze ${ }^{24,25}$ are shown for the system water-acetonitrile. In Fig. 2 the excess volume $V_{m}{ }^{E}$ in $\mathrm{cm}^{3} \cdot \mathrm{mol}^{-1}$ is plotted against the mole fraction of acetonitrile for 100,1000 and 2500 bar and for each pressure at 25,50 and $75^{\circ} \mathrm{C}$. The pressure influence is very remarkable: with increasing pressure the inflection point becomes more and more accentuated and at the highest pressures and temperatures the excess volume changes sign for mixtures rich in acetonitrile. In Fig. 3 the pressure derivatives of the excess functions that follow from the eqns (2-4) with the $V_{m}{ }^{E}$ data of Fig. 2 for $x=0.5$ and $T=50^{\circ} \mathrm{C}$ are plotted for the water-acetonitrile system. All derivatives are negative in the pressure range 100 2500 bar. In contrast to $\left(\partial G_{m}{ }^{E} / \partial p\right)_{T, x_{i}}$ is monotonous, $\left(\partial H_{m}{ }^{E} / \partial p\right)_{T, x_{i}}$ and $\left(\partial S^{E} / \partial p\right)_{T, x_{i}}$ run through minima between 500 and 1000 bar which correspond to inflection points in the $H^{E}(p)$ and $S^{E}(p)$ curves respectively.

Figure 2 shows that the absolute values of the excess volumes $V_{m}{ }^{E}$ are small in comparison to the molar volumes $V_{m}$ themselves whereas the variations of the excess volumes with pressure, temperature and composition can be important and comparable to those of the molar volumes. It follows that an equation of state based on the excess volume as a function of pressure, temperature and composition should be much more promising than one based on the molar volumes. Since nearly nothing is known up to now the problem of an equation of state for mixtures is still a wide field for future research activities (for a compilation see Ref. 111).

Since calorimetric data such as heat capacities of mixtures or enthalpies of mixing ${ }^{26}$ are practically completely lacking at high pressures, most thermodynamic information has to be deduced up to now from high pressure phase equilibria and critical phenomena where our knowledge is much better (for books see Refs. 7, 8, 27; for review articles see Refs. 28-35, for experimental techniques see Refs. 36, 75). 


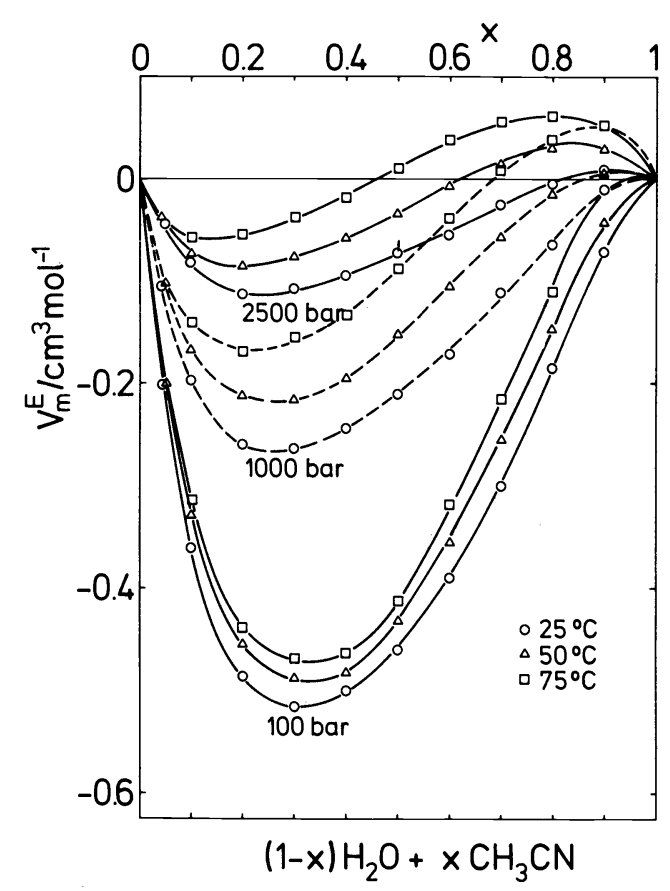

Fig. 2. Molar excess volumes $V_{m}{ }^{E}$ in the system $(1-x)$ water $+x$ acetonitrile as a function of pressure, temperature and mole fraction (according to results of Götze ${ }^{24}$ ).

\section{LIQUID-LIQUID EQUILIBRIA}

In Fig. 4 all types of pressure dependence of liquid-liquid equilibria in binary systems that are presently known are schematically represented; ${ }^{29-33}$ examples exist for all types except those with a question mark (Figs. $4 \mathrm{~g}$, $4 \mathrm{k}, 40,4 \mathrm{~s})$.

In the first vertical column on the left the different types of temperature-mole fraction isobars are represented, i.e. those with upper critical solution temperatures (UCST's, Fig. 4a), lower critical solution temperatures (LCST's, Fig. 4b), closed loops (Fig. 4c) and a hyperbolic-like type (Fig. 4d).

In the first horizontal row pressure-mole fraction isotherms (Fig. $4 \mathrm{e}-\mathrm{h}$ ) that belong to the types of pressure

$\dagger$ It has, however, been shown that the assumption of $G_{m}$ being analytical at a critical solution point is doubtful; for an explicit critical discussion see Refs. 7, 31, 35. dependence given in Figs. 4i-v are represented schematically. Their shapes correspond remarkably well to the temperature-composition diagrams for constant pressure (Figs. 4a-d) demonstrating that pressure and temperature are equivalent thermodynamic variables.

The second horizontal row shows that with increasing pressure upper critical solution temperatures will either decline (Fig. 4i) or rise (Fig. 4 j) or run through a temperature minimum (Fig. 4l).

The third horizontal row demonstrates that with increasing pressure lower critical solution temperatures may either rise (Fig. $4 \mathrm{~m}$ ) or decline (Fig. 4n) or run through a temperature maximum (Fig. 4p).

The pressure dependence of closed loops is schematically shown in the fourth horizontal row: closed loops may either shrink with increasing pressure and disappear completely at a definite pressure in the three-dimensional temperature-pressure-mole fraction space (Fig. 4q) or only appear at higher pressures (Fig. 4r) or resemble hyperboloids (Fig. 4t); examples of types $4 r$ and $4 t$ have been found in binary mixtures of 2-, 3- and 4methylpyridine with water and heavy water. ${ }^{29-34}$

Immiscibility surfaces of a saddle-like type such as shown in the fifth horizontal row have also been found, e.g. in mixtures of methane with hydrocarbons (Fig. 4u) or of sulfur with hydrocarbons (Fig. $4 \mathrm{v}$ ). ${ }^{29-33}$

Examples for all types represented in this Figure have been summarized elsewhere. ${ }^{29-34}$ Here only one example for type $4 \mathrm{j}$ will be given.

In Fig. 5 some very recent results of $\mathrm{Paas}^{40}$ are shown for the methane-tetrafluoromethane system. In Fig. 5a isobaric temperature-mole fraction profiles are plotted which exhibit upper critical solution temperatures that rise with increasing pressure. In Fig. 5b the corresponding isothermal pressure-mole fraction which exhibit lower critical solution pressures, are given.

It has been shown by several authors ${ }^{6-8,29-35,37}$ that some thermodynamic information can be obtained from the pressure dependence of critical solution temperatures. With the assumption that $G_{m}$ is analytic $\dagger$ at and near a critical solution point eqn (8) and with the additional assumption of a regular solution relation (9) hold for the pressure dependence of the critical solution temperature in a demixing binary system

$$
\frac{\mathrm{d} T_{\mathrm{c}}}{\mathrm{d} p}=\frac{T_{\mathrm{c}} \cdot\left(\partial^{2} V_{m}{ }^{E} / \partial x^{2}\right)_{c}}{\left(\partial^{2} H_{m}{ }^{E} / \partial x^{2}\right)_{c}}
$$

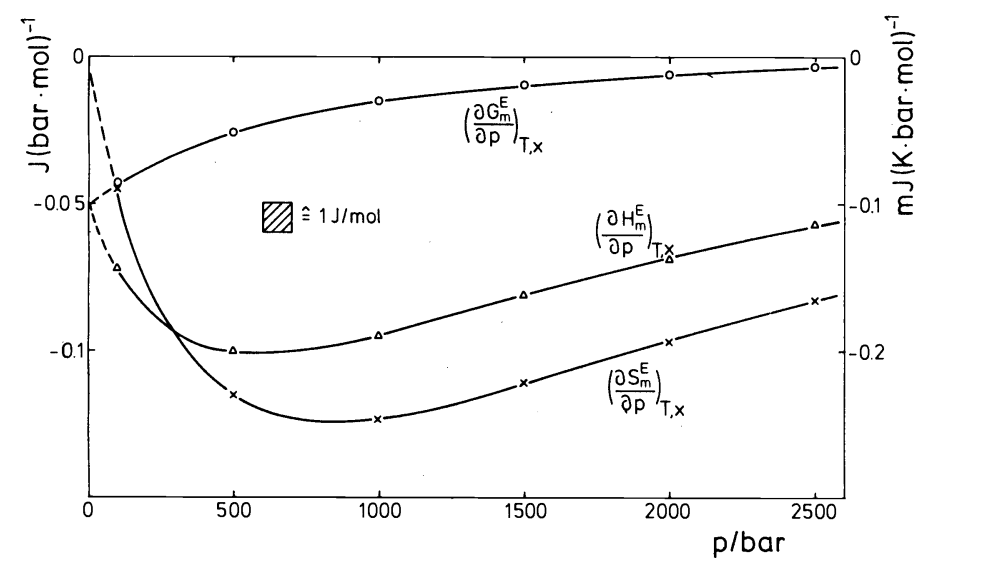

Fig. 3. Pressure dependence of the molar excess functions in the system $(1-x)$ water $+x$ acetonitrile: $\left(\partial G_{m}{ }^{E} / \partial p\right)_{T, x_{i}}$, $\left(\partial H_{m}{ }^{E} / \partial p\right)_{T, x_{i}}$ and $\left(\partial S_{m}{ }^{E} / \partial p\right)_{T, x_{i}}$ as a function of pressure at $T=323.15 \mathrm{~K}$ and $x=0.5$ (according to results of Götze $\left.{ }^{24}\right)$. 


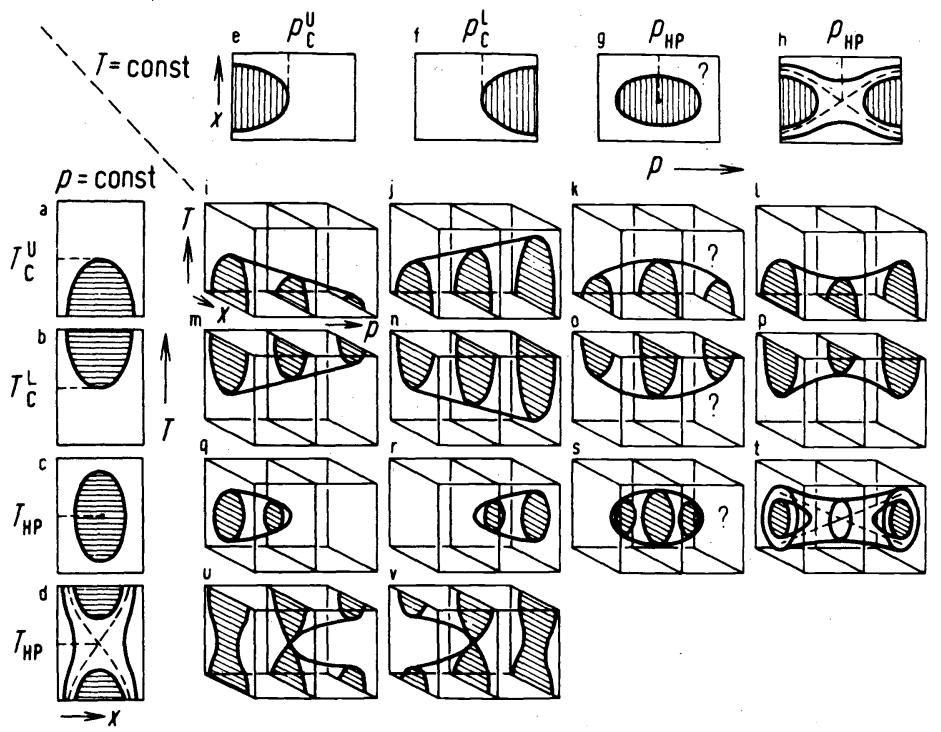

Fig. 4. Pressure effects on immiscibility phenomena in liquid binary systems (according to Refs. 30, 32; see text).
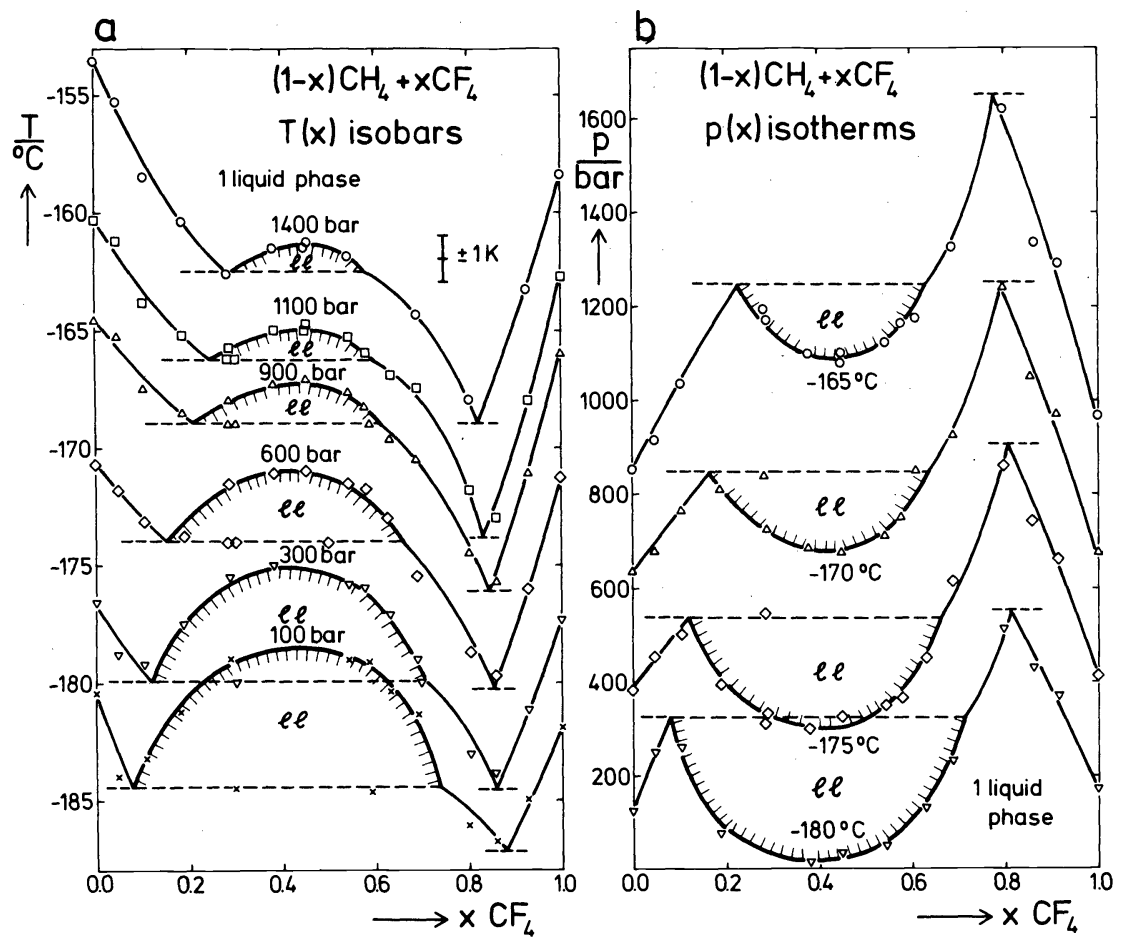

Fig. 5. Phase behaviour of the system $(1-x)$ methane $+x$ tetrafluoromethane at elevated pressures (according to results of $\mathrm{Paas}^{40}$ ). (a) $T(x)$ isobars; (b) $p(x)$ isotherms.

$$
\frac{\mathrm{d} T_{c}}{\mathrm{~d} p}=\frac{T_{c} \cdot V_{m c}^{E}}{H_{m c}^{E}} .
$$

It has to be kept in mind, however, that the conditions for the validity of relation (9) in general are largely oversimplified. $\dagger$ For the system methanetetrafluoromethane it follows from the existence of upper critical solution temperatures (corresponding to $H_{c}{ }^{B}>0^{6-}$ ${ }_{8,29-34,37}$ ) and from the positive sign of $d T_{c} / d p$ obtained

†It has, however, been shown that the assumption of $G_{m}$ being analytical at a critical solution point is doubtful; for an explicit critical discussion see Refs. 7, 31, 35. experimentally ${ }^{40}$ that $V_{m}^{E}$ should be positive, a result that had already been known for this system from normal pressure measurements by Croll and Scott. ${ }^{38}$ Also Paas $^{40}$ could show that regular solution theory ${ }^{39}$ describes quite well the sign and the order of magnitude of $d T_{c} / d p$ in this system.

For systems of type $t$ in Fig. 4 the molar excess enthalpy $H_{m}{ }^{E}$ should have to change its sign from minus (corresponding to LCST's) to plus (corresponding to UCST's) with increasing temperature at constant pressure and it follows from eqn (9) that the molar excess volume $V_{m}{ }^{E}$ should have to change its sign from minus to plus with increasing pressure at constant temperature. ${ }^{29-34}$ The 
curious result is that for these systems that deviate very much from ideality, the molar excess enthalpy $H_{m}{ }^{E}$ and the molar excess volume $V_{m}^{E}$ should both nearly vanish just between the two immiscibility surfaces in Fig. 4t. The change of the sign of the excess volume has already been affirmed experimentally by Engels ${ }^{18-20}$ for the system 3methylpyridine- $\mathrm{H}_{2} \mathrm{O}$.

Liquid-liquid equilibria in ternary systems have been investigated most frequently at normal and low pressure, but for high pressure the experimental data are very scarce. $^{29-34}$ Recently the liquid-liquid equilibria in the ternary system tetrafluoromethane-trifluoromethaneethane have been studied as a function of pressure by Peter $^{42,43}$ and Paas. ${ }^{44}$

For aqueous solutions of organic compounds the influence of added salts on the mutual miscibility has also been studied under pressure in some cases. ${ }^{45,46} \mathrm{~A}$ rather simple example is given in Fig. 6 where the upper and the lower solution temperatures are plotted for the system 1propanol-water-potassium chloride according to measurements of Russo; ${ }^{45}$ the mass ratio water/1-propanol being kept constant at a value of 1.5. Figure 6a gives the solution temperatures as a function of the amount of potassium chloride added at normal pressure and Fig. $6 \mathrm{~b}$ shows the solution temperature as a function of pressure for a mixture of constant composition. There is a striking analogy between Figs. $6 \mathrm{a}$ and $6 \mathrm{~b}$, increasing the pressure having a similar effect as decreasing the salt content.

Systems such as shown in Fig. 6 are well suited to study the rate of liquid-liquid phase separation. Starting from concentrations, temperatures and pressures in the homogeneous region just below the plotted curves heterogeneous states can be reached by a relatively small temperature increase and the rate of demixing is obtained from measuring the turbidity as a function of time. Measurements were made by $\mathrm{Jost}^{47}$ and $\mathrm{Limbach}^{48}$ with a temperature jump apparatus that has been developed for the investigation of fast reactions in solution under high pressure. ${ }^{49}$ Here the temperature jump was created within microseconds by discharging a high voltage capacitor through the solution. The measuring cell with optical windows was mounted in a high pressure autoclave. The intensity of the transmitted light and of the light scattered through an angle of 90 degrees could be measured simultaneously as a function of time, stored in a transient recorder and registered afterwards with a normal recorder. In Fig. 7 the recorder traces thus obtained are presented for one experiment on the system 1-propanol-water-potassium

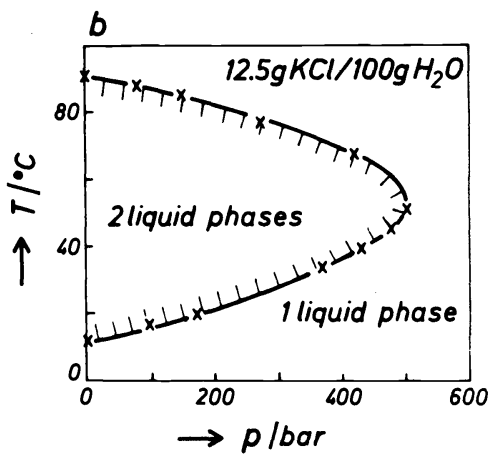

Fig. 6. Salt and pressure effects on liquid-liquid immiscibility phenomena in the system 1-propanol-water-potassium chloride (according to results of Schneider and Russo ${ }^{45} ; \mathrm{w} \%$ water/w\% 1-propanol = const. $=1.5$ ).

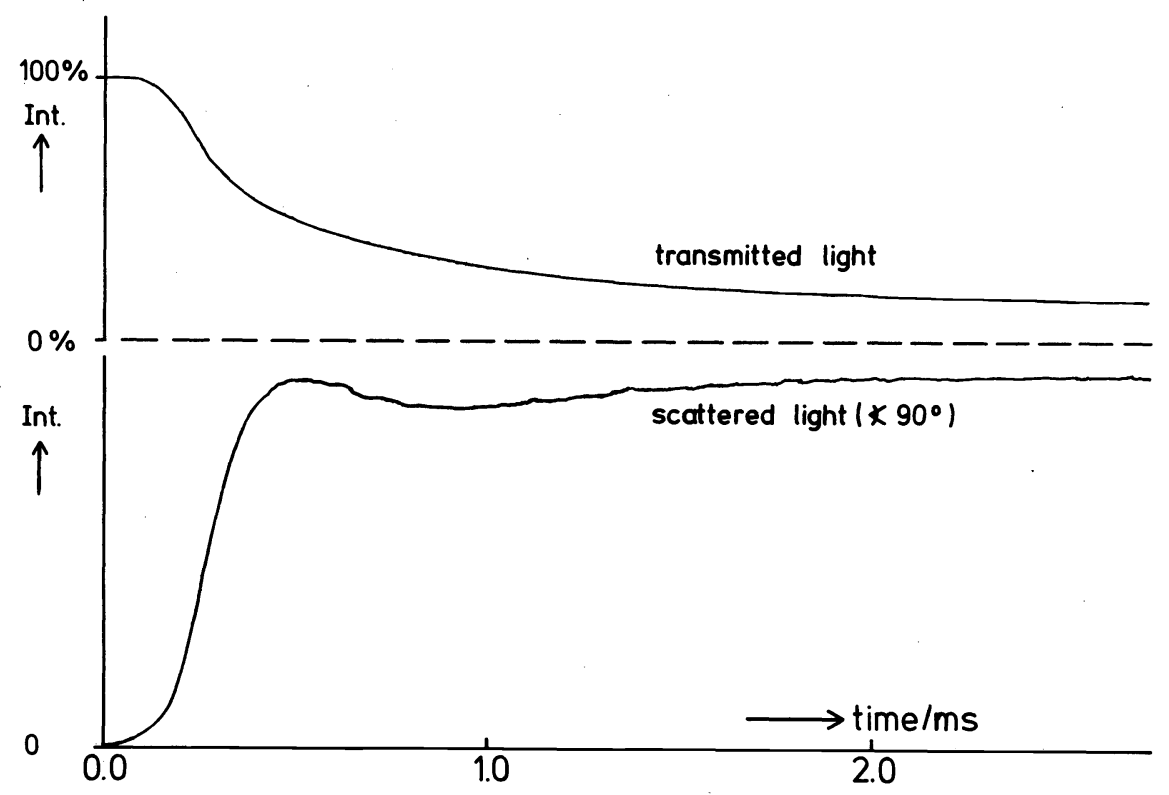

Fig. 7. Rate of liquid-liquid phase separation system 1-propanol-water-potassium chloride (according to results of Limbach ${ }^{48} ; \Delta T=13^{\circ} \mathrm{K} ; \lambda=497 \mathrm{~nm} ; \mu \quad$ । bar; concentrations: 50.3 wt\% 1-propanol, 44.5 wt\% water, $5.2 \mathrm{wt} \%$ potassium chloride). 
chloride at $1 \mathrm{bar} ;{ }^{48}$ similar measurements have also been performed on the system pyridine-water-potassium chloride at elevated pressures. ${ }^{47}$ In the upper diagram of Fig. 7 the intensity of the transmitted light and in the lower diagram the intensity of the scattered light are registered as a function of time. The transmitted light decreases to nearly zero transmission and the scattered light accordingly increases to a nearly constant value within less than one millisecond. The initial maximum in the the intensity of the scattered light can be explained qualitatively from the growth of the scattering particles during the time of the experiment. The curves show that induction times greater than some tenth of a millisecond are absent and it follows from a rough estimation that the formation and the ageing of the scattering droplets of a second liquid phase is essentially diffusion controlled.

\section{LIQUID-GAS EQUILIBRIA}

In Fig. 8a the well-known three-dimensional pressuretemperature-mole fraction surface is represented for the liquid-gas equilibria of a binary system in a simple case, $x$ being the mole fraction of the less volatile component II. The dashed lines are the vapour pressure curves of the pure components I and II. They end at the gas-liquid critical points CP I and CP II of the pure components. For each pressure-mole fraction isotherm the binary critical point is situated at the maximum of the isothermal pressure-mole fraction profile; the line that connects the critical points of all isotherms is the binary critical curve.

The phase equilibria and the critical phenomena in binary fluid mixtures are most easily discussed with the aid of the pressure-temperature projection of this critical line, the so-called critical locus curve. Here the critical locus curve is not interrupted; some important types are schematically represented in Fig. 8b. At temperatures and pressures beyond the critical locus curve the two components of the binary system are miscible in all proportions (for examples and Refs. see Refs. 7, 8, 29-33, 50).

\section{GAS-GAS EQUILIBRIA}

The critical phase behaviour of binary mixtures, however, is not always so simple as that represented in Figs. $8 \mathrm{a}$ and $8 \mathrm{~b}$. In Fig. 9a the phase behaviour of systems exhibiting gas-gas equilibria is schematically shown in a three-dimensional representation. Here the critical locus curve is interrupted. The branch that starts from the critical point CP II of the less-volatile component II does not end at the critical point of pure component I as in Fig. 8 but runs through a temperature minimum corresponding to a so-called gas-gas equilibrium of the second type
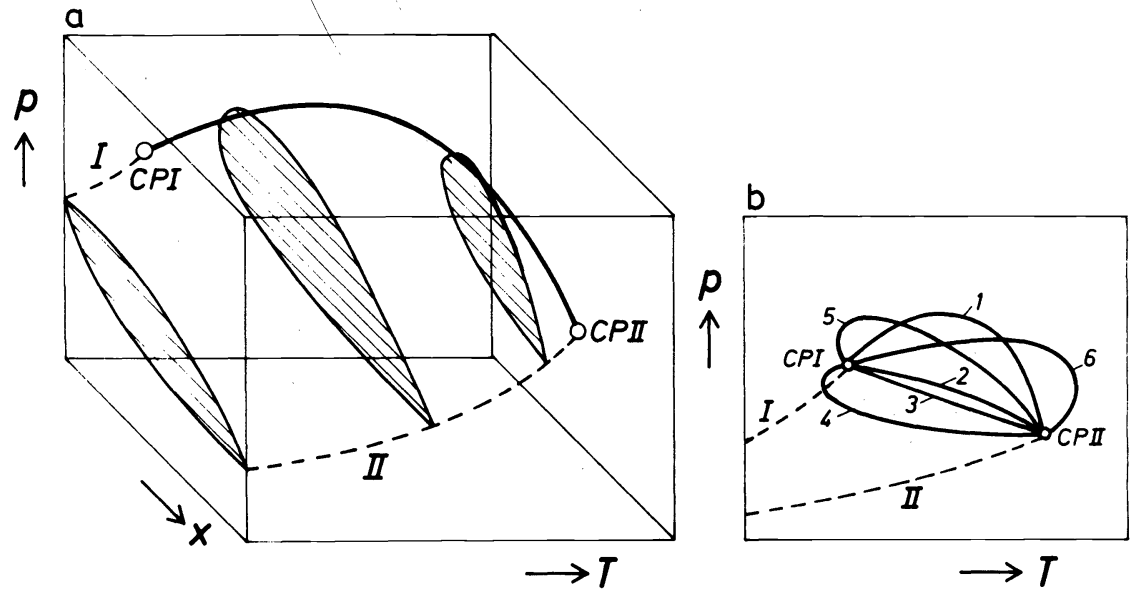

Fig. 8. Liquid-gas equilibria in binary systems (schematically; see text). (a) Three-dimensional representation in the $T-p-x$ space; (b) $p(T)$ projection of the diagram in (a).
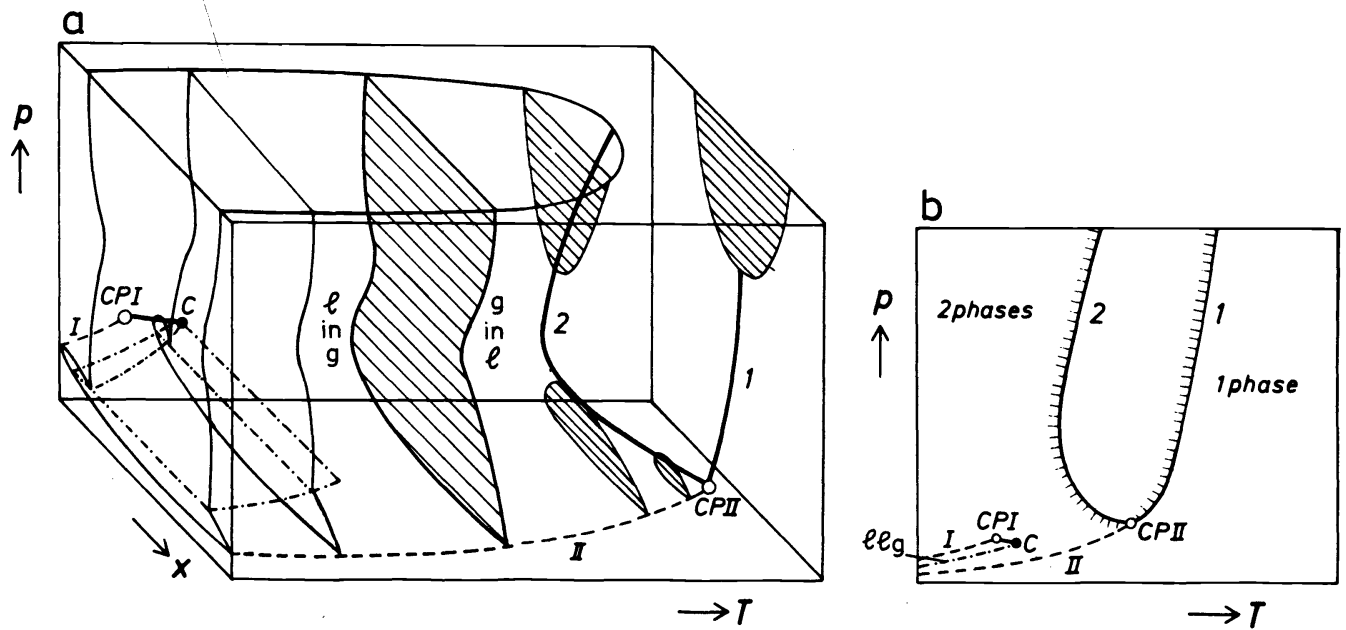

Fig. 9. Gas-gas equilibria in binary systems (schematically; see text). (a) Three-dimensional representation in the $T$ $p-x$ space; (b) $p(T)$ projection of the diagram in (a). 
(curve 2) or directly tends to increasing temperatures and pressures corresponding to a gas-gas equilibrium of the first type (curve 1). The corresponding $p(T)$ projections are represented schematically in Fig. $9 \mathrm{~b}$.

These phase separation effects were predicted by van der Waals ${ }^{51}$ and discussed in detail by Kamerlingh Onnes and Keesom as early as $1907 .^{52}$ Type 2 was found for the first time in 1940 by Krichevskii and co-workers ${ }^{53}$ in the system nitrogen-ammonia and type 1 in 1952 by Tsiklis $^{54}$ in the system helium-ammonia. In the mean time similar phase separation effects have been detected in some fifty other systems; ${ }^{7,27-34,50}$ up to now no temperature maximum on the critical curve, however, has been found such as originally predicted by van der Waals.

At a first glance these somewhat exotic types of phase behaviour might seem to be of academic interest only to normal thermodynamicists. One has to realize, however, that the exhibition of gas-gas equilibria will rather be the rule than the exception for mixtures where the components differ more and more in size, structure and/or polarity e.g. for solutions of a gas in a liquid. Here the right branch of the middle isotherm in Fig. 9a (marked with " $g$ in 1") corresponds to the solubility of gas I in liquid II as a function of pressure, whereas the left hand branch (marked with " 1 in g") corresponds to the solubility of liquid II in gas I, both on a mole fraction basis. It is an interesting fact that for systems of this type, both solubilities will run through a maximum mole fraction value with increasing pressure; here the numerator of the right hand side of the coexistence eqn $(10)^{6,7}$

$$
\left(\frac{\partial x_{2}}{\partial p}\right)_{T, \sigma}=\frac{x_{1}^{\prime \prime}\left(V_{1}^{\prime}-V_{1}^{\prime \prime}\right)+x_{2}^{\prime \prime}\left(V_{2}^{\prime}-V_{2}^{\prime \prime}\right)}{\left(\partial^{2} G_{m} / \partial x_{2}^{2}\right)_{T, p}^{\prime}\left(x_{2}^{\prime}-x_{2}^{\prime \prime}\right)}
$$

will become zero, $V_{i}$ being the partial volume and ' and " the indices for the coexisting phases.

Examples for gas-gas equilibria have been summarized in some books, e.g. by Tsiklis ${ }^{27}$ and Rowlinson ${ }^{7}$ and in several review articles. ${ }^{28-34}$ Here only some results on inert gas systems will be reviewed in Fig. 10 where parts of the critical locus curves of some helium binaries, and of the vapour pressure curves of the less volatile components respectively are plotted making use of a compilation by Streett. ${ }^{55}$ Whereas helium-hydrogen, ${ }^{56}$ heliumnitrogen ${ }^{57}$ and helium-argon ${ }^{55,58}$ exhibit gas-gas equilibria of the second type and helium-neon ${ }^{59}$ shows a tendency for such a phase behaviour, gas-gas equilibria of the first type have been found in the systems helium-methane, ${ }^{60}$ helium-xenon ${ }^{61}$ and helium-carbon dioxide. ${ }^{62}$ According to Schouten and Trappeniers neon-krypton ${ }^{63}$ resembles to the helium-argon system.
The gas-gas equilibria found in the helium-hydrogen system seem to have important consequences for planetary atmospheres as has been recently reported by Streett. ${ }^{56}$ The same author has also discussed the limits of gas-gas equilibria. ${ }^{64}$ In principle there is no limit of the gas-gas critical curve at higher temperatures and pressures. In many cases it will disappear below the crystallization surface of the system at very high pressures but it may also persist up to very high temperatures and pressures perhaps even to the limits at which atomic and molecular structure begin to break down. ${ }^{64}$

\section{TRANSITIONS BETWEEN LIQUID-GAS, LIQUID-LIQUID AND GAS-GAS EQUILIBRIA}

Up to now the three different types of two-phase equilibrium in fluid mixtures namely liquid-liquid, liquidgas and gas-gas equilibria have been discussed separately. During the last decade systematic high-pressure investigations, however, have shown that the limits between these three forms of heterogeneous phase equilibrium in fluid mixtures are not well defined and that continuous transitions occur ${ }^{30-34}$ the transition types sometimes being of considerable practical interest.

The discussion of this question will start from Fig. 11 where the phase behaviour and the critical phenomena are schematically represented for a binary system exhibiting separation into two liquid phases. ${ }^{33}$ For the type in Figs. 11a and 11b the critical curve liquid-gas (lg) is not interrupted and runs through the usual pressure maximum. At temperatures far below the critical temperature of the pure more volatile component I separation into two liquid phases additionally takes place. The branch 11 of the critical curve corresponds to upper critical solution temperatures as a function of pressure that are slightly raised with increasing pressure.

The more the mutual miscibility of the two components decreases the more the branch 11 of the critical curve is displaced to higher temperatures. It can finally penetrate the ranges of temperature and pressure for the critical phenomena liquid-gas and may pass continuously into the critical curve lg whereas the branch of the critical curve starting from the critical point of the pure component $I$ ends at a so-called critical end point $C$ on the three-phase line liquid-liquid-gas (Figs. 11c and 11d).

For still lower mutual miscibility of the components critical locus curves without any pressure maximum or minimum may be obtained such as indicated in Fig. 11d by a dotted line. Since a phase behaviour of this type is attributed to gas-gas equilibria of the second type, continuous transitions between liquid-gas, liquid-liquid and gas-gas equilibria should be possible.

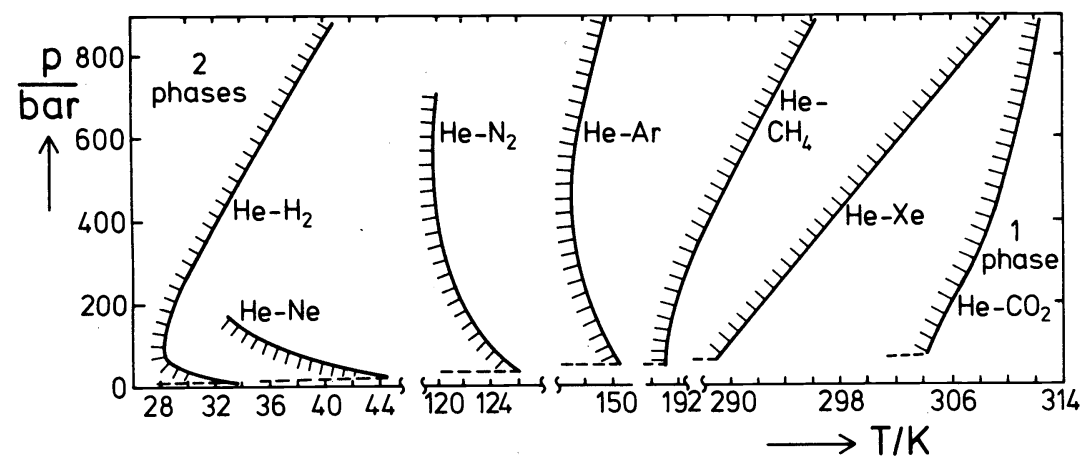

Fig. 10. Critical locus curves of binary helium systems (according to a similar compilation by Streett ${ }^{55}$; for details and references see text). 

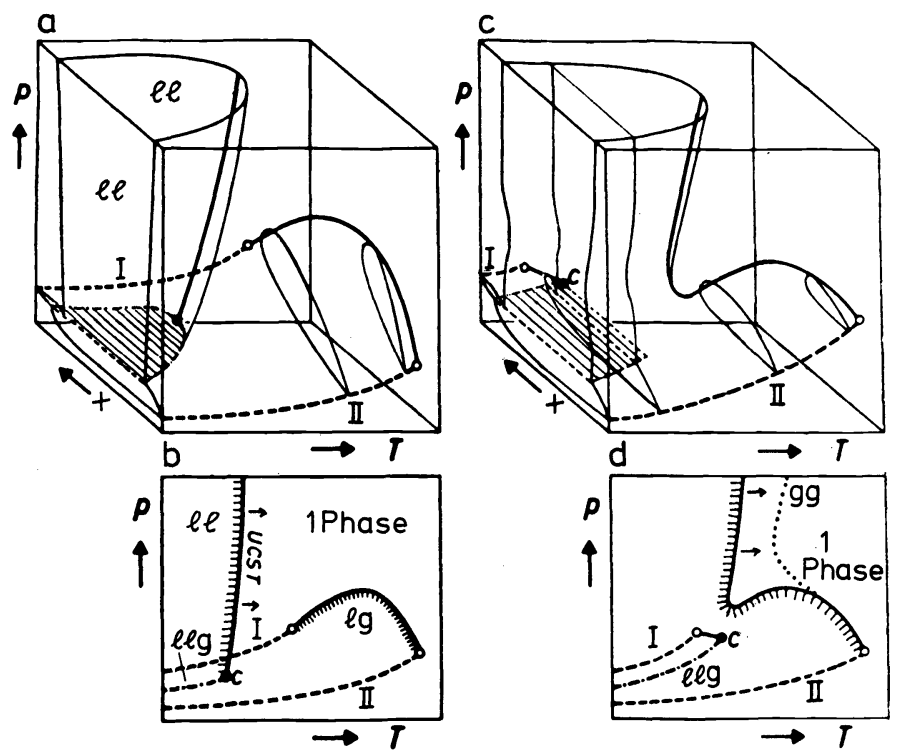

Fig. 11. Phase behaviour of a binary system showing liquid-liquid immiscibility (schematically; see text). (a) and (c) Three-dimensional representation in the $T-P-X$ space; (b) $p(T)$ projection of the diagram in (a); (d) $p(T)$ projection of the diagram in (c).

In order to prove this hypothesis series of binary systems were studied where one constant component I such as carbon dioxide, methane, ethane, ethylene, water etc. was combined with a component II that was systematically altered in size, structure and polarity, the phrase "family" being proposed for such a series of related binary systems. ${ }^{64}$

In Fig. 12 the carbon dioxide family is discussed as a first example. For binary mixtures of carbon dioxide with octane $^{66}$ the liquid-gas critical curve lg runs through the usual pressure maximum. At much lower temperatures additionally separation into two liquid phases is found, the upper critical solution temperatures rising steeply with increasing pressure. No superposition of the critical phenomena liquid-gas and liquid-liquid occurs in this system. If octane is replaced by a higher alkane the mutual miscibility decreases and the branch of the

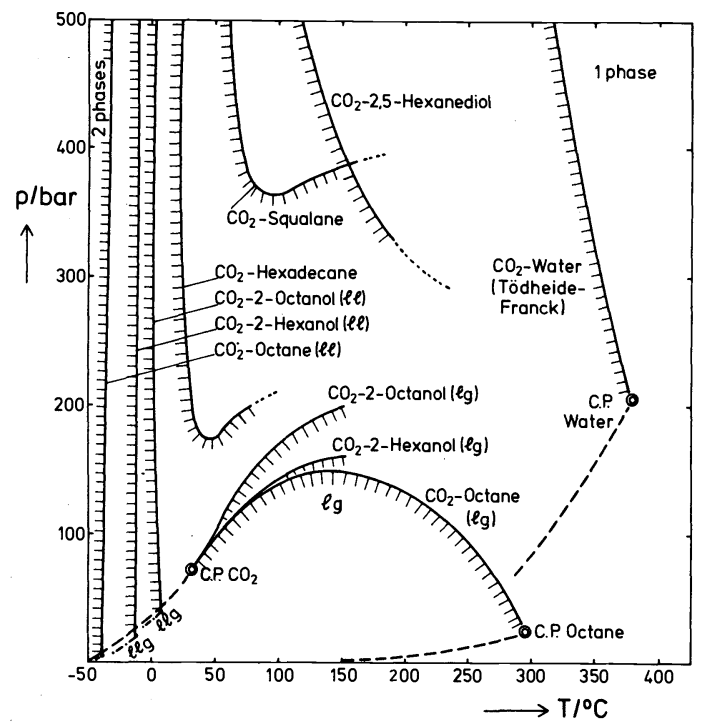

Fig. 12. Critical locus curves of binary carbon dioxide systems (for details and references see text). critical curve that corresponds to liquid-liquid equilibria is displaced to higher temperatures. For carbon dioxidehexadecane ${ }^{66}$ it penetrates the ranges of temperature and pressure for the critical phenomena liquid-gas and the critical curve liquid-liquid (ll) merges continuously into the critical curve liquid-gas $(\mathrm{lg})$, a pronounced pressure minimum and a slight temperature minimum being found. For carbon dioxide-squalane ${ }^{67} \quad(=2,6,10,15,19,23$-hexamethyltetracosane) the mutual miscibility is still lower and the critical curve liquid-liquid (ll) is displaced to even higher temperatures, the pressure minimum of the critical curve becoming less pronounced. For even higher alkanes than squalane critical locus curves without any pressure maximum or minimum may be obtained. ${ }^{67}$

The phase behaviour of carbon dioxide-2-hexanol ${ }^{65}$ and of carbon dioxide-2-octanol ${ }^{65}$ corresponds completely to that of carbon dioxide-octane, whereas the system carbon dioxide-2,5-hexanediol ${ }^{65}$ resembles that of carbon dioxidesqualane without showing, however, any pressure minimum or maximum. According to measurements of Tödheide and Franck ${ }^{68}$ the critical curve of the carbon dioxide-water system runs through a temperature minimum at approximately 1500 bar showing thus a typical gas-gas phase behaviour of the second type.

These types of phase behaviour in fluid carbon dioxide systems are of increasing practical interest since supercritical carbon dioxide may become an important solvent for industrial extractions, especially in the food and pharmaceutical industry where substances with low thermal stability have to be separated or purified.94,5 Some patents have already been given in this field. ${ }^{69}$ Additionally supercritical carbon dioxide is the favourite mobile phase in supercritical fluid chromatography (SFC) ${ }^{70-74}$

In Figs. 13 and 14 the methane family is treated. ${ }^{30-33,76,77,79,80}$ Figure 13 shows the pressure-temperature projections of the phase diagrams of several binary hydrocarbon systems and of the systems methaneammonia ${ }^{78}$ and helium-methane. ${ }^{60}$ The critical curve of the rather curious type of Fig. 13c consists of two branches. That at low temperatures corresponds to upper critical solution temperatures; the other branch of the critical 


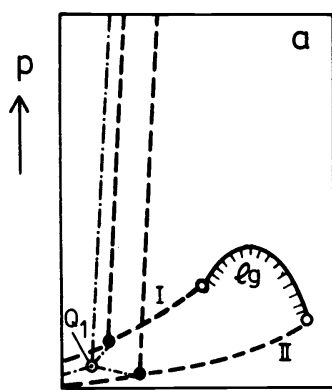

$\mathrm{CH}_{L}$ - propane

$\mathrm{C}_{2} \mathrm{H}_{6}$-decane

$\mathrm{C}_{3} \mathrm{H}_{8}$-squalane

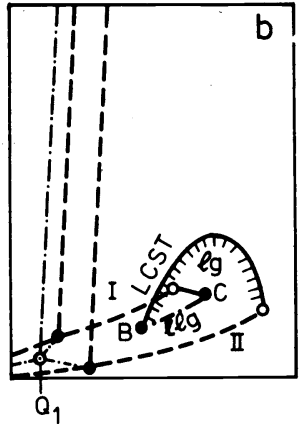

$\mathrm{CH}_{4}$-hexone

$\mathrm{C}_{2} \mathrm{H}_{6}$-squalane

$\mathrm{C}_{3} \mathrm{H}_{8}$-lubric. oils

$\mathrm{HC}$ - polymers

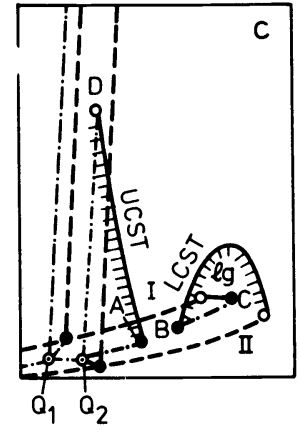

$\mathrm{CH}_{4}-1$-hexene

$\mathrm{CH}_{4}$-3,3-dimethylpentane

HC - polymers

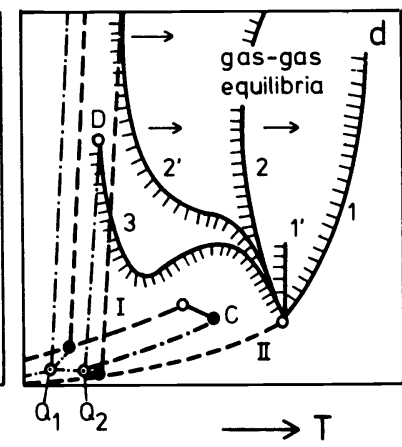

$\mathrm{CH}_{4}$-methylcyclopentane (3)

$\mathrm{CH}_{4}$-methylbenzene (2')

$\mathrm{CH}_{4}$-squalane (2.)

$\mathrm{CH}_{4}-\mathrm{NH}_{3}(2)$

$\mathrm{He}-\mathrm{CH}_{4}(1)$

$$
\begin{aligned}
- & =\text { critical } p(T) \text { curve } & Q_{1}=g \ell s(I / s(I) \\
---=\text { vapour pressure curve } & & Q_{2}=g \ell \ell_{s}(I)
\end{aligned}
$$

Fig. 13. $p(T)$ projections of the phase diagrams of binary hydrocarbon systems (schematically; see text).

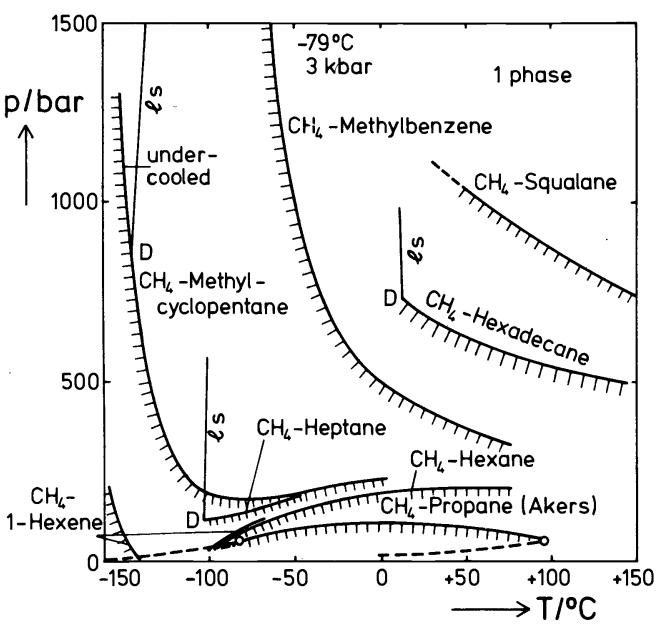

Fig. 14. Critical locus curves of binary methane-hydrocarbon systems (for details and references see text).

curve first corresponds to lower critical solution temperatures for liquid-liquid phase separation and then merges continuously into the critical curve liquid-gas that ends at the critical point of the less volatile component II (e.g. methane-1-hexene, ${ }^{79}$ methane-3,3-dimethylpentane ${ }^{80}$ ). This somewhat exotic type of phase behaviour is of considerable practical interest and seems to be the fundamental type of phase behaviour for mixtures of hydrocarbons differing very much in size, e.g. for solutions of polymers in hydrocarbon solvents (see Refs. 7, 81).

With increasing mutual miscibility (e.g. for smaller differences in size and/or polarity) the branch that corresponds to upper critical solution temperatures in Fig. $13 \mathrm{c}$ is displaced to lower temperatures and may disappear below the crystallization surface such as shown in Fig. 13b (e.g. methane-hexane, ${ }^{76}$ ethane-squalane, ${ }^{82}$ propanelucricating oils, ${ }^{7}$ polymers in a hydrocarbon solvent ${ }^{7,81}$ ); for further increasing mutual miscibility the common type of Fig. 13a results (e.g. methane-propane, ${ }^{83}$ ethanedecane ${ }^{84}$ propane-squalane ${ }^{65}$ ). Figure $13 \mathrm{~d}$ corresponds to decreasing mutual miscibility in comparison to type 13c: Consecutively type 3 (e.g. methane-methylcyclo- pentane ${ }^{76,77}$ ), type $2^{\prime}$ (e.g. methane-methylbenzene, ${ }^{77}$ methane-squalane ${ }^{65}$ ) and type 2 result, the latter corresponding to a gas-gas system of the second type (e.g. methane-ammonia ${ }^{78}$; finally type 1 is obtained, which corresponds to a gas-gas system of the first type (e.g. helium-methane $e^{60}$ ).

Experimental data for the schematic types of Fig. 13 are given in Fig. 14, where the critical locus curves for methane binaries with hydrocarbons of sizes from propane to squalane are plotted. Methane-propane ${ }^{83}$ has a noninterrupted critical curve liquid-gas according to type 13a. Methane-hexane ${ }^{76}$ belongs to type $13 \mathrm{~b}$ and methane-1hexene $^{77,79}$ to type 13c. The critical curves of the methane-heptane ${ }^{76}$ and the methanemethylcyclopentane $^{76,77}$ systems run through pressure minima according to type 3 in Fig. 13d whereas the critical curves of methane-methylbenzene, ${ }^{77}$ methanehexadecane ${ }^{65}$ and methane-squalane ${ }^{65}$ have a monotonous shape such as type 2 in Fig. 13d. This kind of phase behaviour is of great practical importance for the fabrication of high-pressure polyethylene since the methane-hexadecane ${ }^{65}$ form has also been found for solutions of polyethylene in ethylene by Ehrlich ${ }^{85}$ and Steiner and Horlé. 86

It has been shown in Figs. 11-14 that a large pattern of transition types between typical liquid-gas, typical liquidliquid and typical gas-gas equilibria exist in fluid mixtures at high pressures that are of considerable practical interest in some cases. Quite similar phenomena have also been found in mixtures of helium with inert gases (see Fig. 10), of hydrocarbons of medium size with water at much higher temperatures, ${ }^{25,29-34}$ in ammonia binaries ${ }^{27-}$ $34,53,44,7,109$ etc.; similar investigations on ethylene and ethane binaries are underway. ${ }^{65}$ All these results give evidence that the hypothesis of transitions between all types of two-phase equilibrium in fluid mixtures is useful in understanding the great variety of phase relationships and in giving a certain order to many different types of critical phenomena in fluid mixtures.

Scaling law studies in mixtures (see Ref. 35) have not yet been performed at high pressures since the high accuracy necessary for these investigations is difficult to obtain under these conditions; just the pressure dependence of the scaling parameters, however, should be of considerable 
experimental and theoretical interest, e.g. because of the great variety of the different $p(x)$ isotherms and/or $T(x)$ isobars that can be sometimes obtained in the same system at high pressures. Although critical phenomena seem to be more or less understood in fluid binary mixtures ${ }^{87}$ much progress is to be expected in the investigation of the phase diagrams and critical phenomena of ternary and multicomponent mixtures under high pressures, e.g. with respect to tricritical points. ${ }^{41}$

\section{CALCULATION OF HIGH-PRESSURE PHASE EQUILIBRIA IN FLUID MIXTURES}

The continuity between all types of two-phase equilibria in fluid mixtures demonstrated in the preceding section is also of interest from a theoretical point of view especially for the calculation of high-pressure phase equilibria in fluid mixtures.

These calculation methods start from the fact that the conditions for phase equilibrium and for critical points are essentially the same for all types of two-phase equilibria in fluid mixtures. For a binary system the conditions for phase equilibrium are given in eqn (11)

$$
G_{m}^{\prime}-x_{m}^{\prime}\left(\partial G_{m} / \partial x_{i}\right)_{p, T}^{\prime}=G_{m}^{\prime \prime}-x_{i}^{\prime \prime}\left(\partial G_{m} / \partial x_{i}\right)_{p, T}^{\prime \prime}
$$

or

$$
\mu_{i}^{\prime}=\mu_{i}^{\prime}
$$

with

$$
i=1 \text { or } 2 \quad \text { for } T^{\prime}=T^{\prime \prime} \text { and } p^{\prime}=p^{\prime \prime}
$$

and for a binary critical point in eqn (12)

$$
\left(\partial^{2} G_{m} / \partial x_{i}^{2}\right)_{c}=0 \quad\left(\partial^{3} G_{m} / \partial x_{i}^{3}\right)_{c}=0
$$$$
\text { for } i=1 \text { or } 2 \text {. }
$$

From the phase equilibrium conditions the phase diagram is deduced, while from the conditions of a critical point the critical curve can be obtained. In most cases, however, the simple conditions for the molar Gibbs energy $G_{m}$ given in (11) and (12) are not applicable but the more complicated corresponding conditions for the molar Helmholtz energy $A_{m}$ have to be used. ${ }^{6,735,37}$ Because of difficulties in the definition of standard states generally no excess functions are used.

The molar Gibbs energy $G_{m}$ or the molar Helmholtz energy $A_{m}$ necessary for the calculations are obtained:

(1) from an equation of state that is often a modified version of the Redlich-Kwong ${ }^{88-95,106}$ or of the van der Waals ${ }^{35,80}$ equation, using sometimes rather sophisticated combining rules for the parameters of the mixtures, or

(2) from theories of mixtures with the use of different combining rules for the potential parameters in a mixture. $^{98-105}$

Calculations of high-pressure phase diagrams in fluid mixtures from an equation of state have been carried out by Wilson, ${ }^{88}$ Prausnitz and Chueh, ${ }^{89}$ Zudkevitch and Joffe, $^{90}$ Joffe, Schroeder and Zudkevitch, ${ }^{91}$ Peter and Wenzel, ${ }^{92}$ Wenzel and Peter, ${ }^{93}$ Peter, Brunner and Riha, ${ }^{94,95}$ Scott and van Konynenburg, ${ }^{80}$ Scott, ${ }^{35}$ Breedveld and Prausnitz, ${ }^{96}$ Renon, Chandron and Asselineau ${ }^{97}$ and others.

Calculations from theories and models have been per- formed by de Swaan Arons and Diepen, ${ }^{61}$ Zandbergen, Knaap and Beenakker, ${ }^{98}$ Tan, Luks and Kozak, ${ }^{99}$ Rigby $e t$ al. ${ }^{100}$ Trappeniers, Schouten and Ten Seldam, ${ }^{101}$ Schouten, Ten Seldam and Trappeniers, ${ }^{102}$ Mulholland and Rehr, ${ }^{103}$ Neff and McQuarrie, ${ }^{104}$ Bartis and Hall ${ }^{105}$, McGlashan, Stead and Warr ${ }^{112}$ and others.

Here only the calculation method using the RedlichKwong equation of state will be treated in more detail for a binary system (see Refs. 92-95). From condition (11), eqn (13) can be deduced

$$
R T \ln \left(x_{i}^{\prime} / x_{i}^{\prime \prime}\right)=\int_{p^{0}}^{p}\left(V_{i}^{\prime \prime}-V_{i}^{\prime}\right) \mathrm{d} p=\int_{V\left(p^{0}\right)}^{V(p)}\left(p_{i}^{\prime}-p_{i}^{\prime}\right) \mathrm{d} V
$$

Here $p_{i}$ is not the partial pressure but is defined as $p_{i}=\left(\partial p / \partial n_{i}\right)_{T, V, x_{j}(j \neq i)} ; p^{0}$ is a (low) reference pressure.

The Redlich-Kwong equation of state (14)

$$
p=\frac{n R T}{(V-n b)}-\frac{a n^{2}}{T^{1 / 2} V(V+n b)}
$$

is then used for the calculation of the integrals in (13) with the mixing rules (15) and (16) for the parameters $a$ and $b$

$$
\begin{aligned}
& a=a_{11} x_{1}^{2}+2 a_{12} x_{1} x_{2}+a_{22} x_{2}^{2} \\
& b=b_{11} x_{1}+b_{22} x_{2} .
\end{aligned}
$$

$a$ and $b$ for the pure components are obtained from $p V T$ data and critical data $a_{12}$ is calculated from (17)

$$
a_{12}=\left(1-k_{12}\right)\left(a_{11} a_{22}\right)^{1 / 2}
$$

where the correction parameter $k_{12}$ is generally fitted to one binary experiment.

In Figs. 15 and 16 some characteristic results are shown that have been obtained with this method by Deiters. ${ }^{106}$ In Fig. 15 experimental $^{107}$ and calculated ${ }^{106}$ data are compared for the pressure-mole fraction isotherm of the system methane-heptane at $477.60^{\circ} \mathrm{K}$; a $k_{12}$ value of 0.1381 was used. The agreement between the experimental data and the calculated curve is quite satisfactory. In Fig. 16 experimental ${ }^{61}$ and calculated ${ }^{106}$ values are compared for helium-xenon at $293.15^{\circ} \mathrm{K}$, this system exhibiting gas-gas equilibria of the first type (see Fig. 10). Here the agreement is not bad, but a $k_{12}$ value of 1.2561 had to be used, the physical meaning of which being doubtful.

In Fig. 17 some results of the theoretical approach of Neff and McQuarrie ${ }^{104}$ are compiled where reduced critical locus curves predicted from the van der Waals onefluid theory are plotted; here pressure and temperature are reduced with the Lennard-Jones 6-12 intermolecular potential parameters $\epsilon_{22}$ and $\sigma_{22}$ of the less volatile component 2 . The first row corresponds to $R_{\sigma}=\sigma_{11} / \sigma_{22}=$ 0.6 and the second row to $R_{\sigma}=0.8$, the curves are labelled with the ratio $\epsilon_{11} / \epsilon_{22}$, and $k_{12}$ is defined by

$$
\epsilon_{12}=\left(1-k_{12}\right)\left(\epsilon_{11} \epsilon_{22}\right)^{1 / 2} \text {. }
$$

A whole sequence of different critical locus curves result, ranging from curves having a negative initial slope without any temperature minimum, through types with a temperature minimum corresponding to gas-gas equilibria of the second type, up to curves that run directly to increasing temperatures and pressures such as are attributed to gas-gas systems of the first type. Decreasing values of 


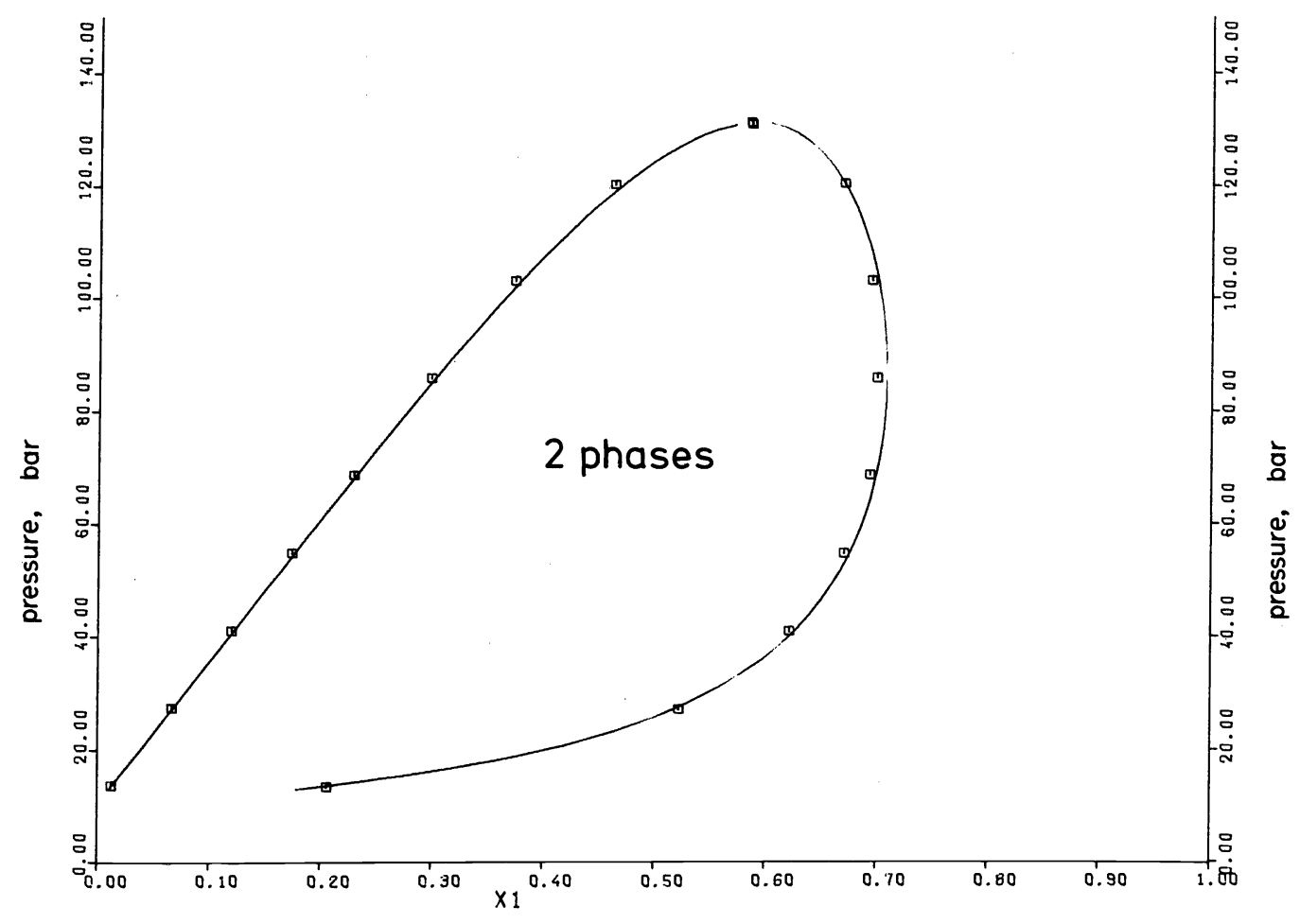

$k_{12}=0.1381$

METHANE/HEPTANE

TEMPERATURE, $477.60 \mathrm{~K}$

Fig. 15. Calculation of high-pressure phase equilibria in binary fluid systems: $p(x)$ isotherm at $477.6^{\circ} \mathrm{K}$ for methane-heptane $\left(\square=\right.$ experimental data ${ }^{107}$, full line $=$ calculated curve ${ }^{106}$; original computer plot; for details see text).
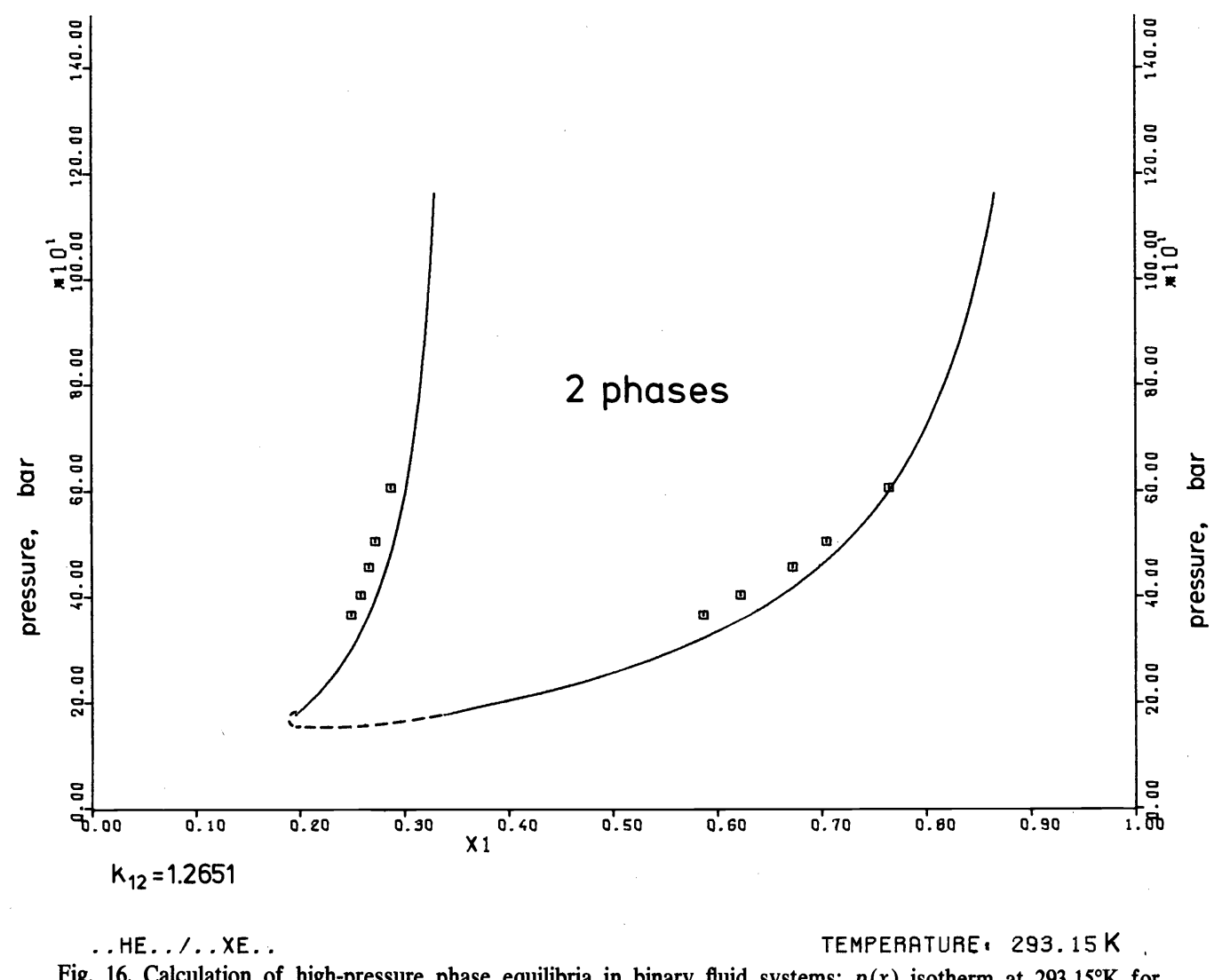

HE. , XE

TEMPERATURE， $293.15 \mathrm{~K}$

Fig. 16. Calculation of high-pressure phase equilibria in binary fluid systems: $p(x)$ isotherm at $293.15^{\circ} \mathrm{K}$ for helium-xenon $\left(\square=\right.$ experimental data ${ }^{61}$, full line $=$ calculated curve ${ }^{106}$; original computer plot; for details see text). 

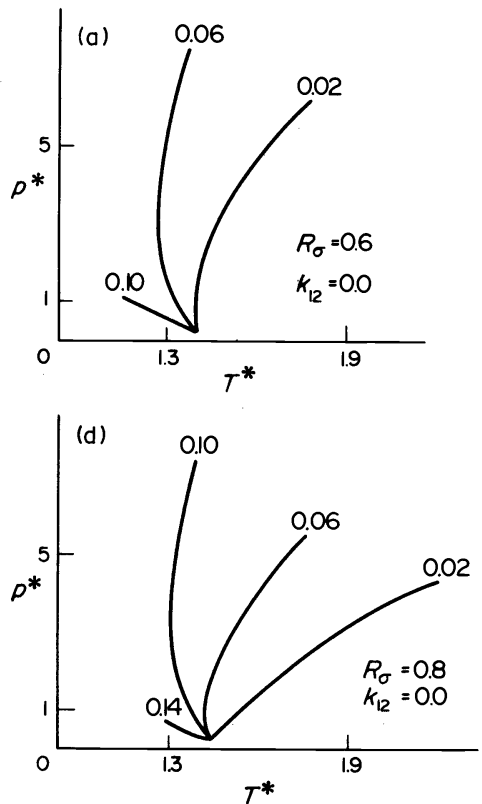
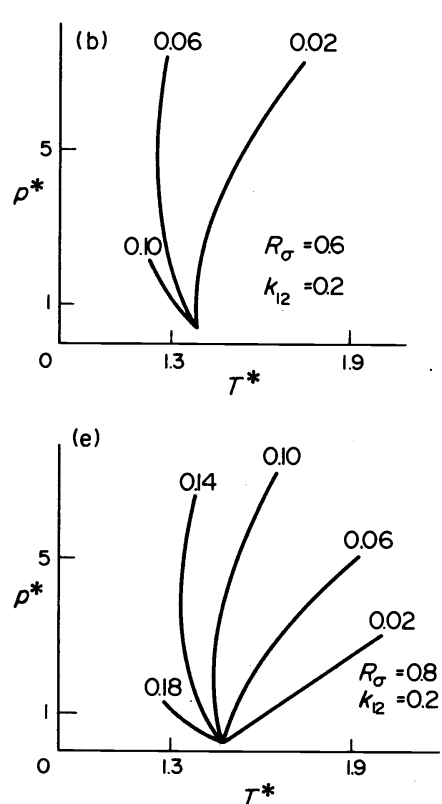
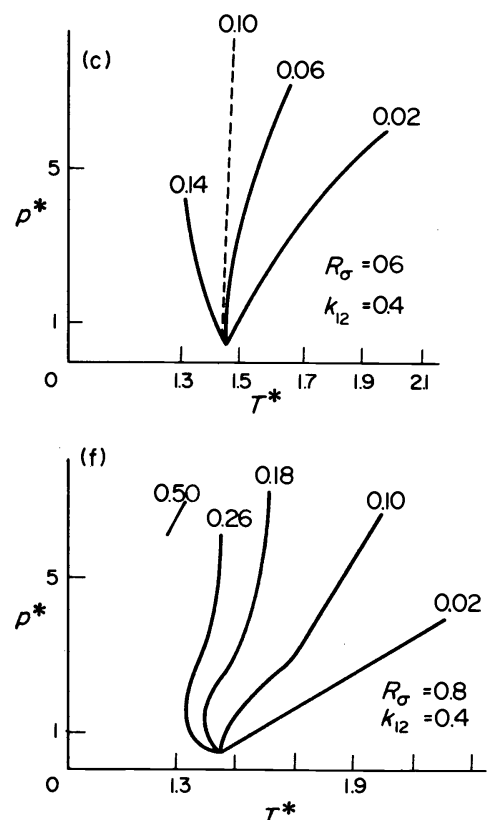

Fig. 17. Critical locus curves predicted by the van der Waals one-fluid theory (according to Neff and McQuarrie ${ }^{104}$; curves are labeled with $\epsilon_{11} / \epsilon_{22} ; R_{\sigma}=\sigma_{11} / \sigma_{22} ;$ for $k_{12}$ see text; $2=$ less volatile component).

$\epsilon_{11} / \epsilon_{22}$ and increasing values of $k_{12}$ increase the tendency to the formation of gas-gas equilibria of the first type; this tendency is partly compensated, however, by increasing difference in size for this model. ${ }^{104}$

\section{PRESSURE DEPENDENCE OF CHEMICAL} EQUILIBRIA IN SOLUTIONS

Since the treatment of reacting mixtures is somewhat outside the scope of the present lecture only some results that have been recently obtained in the field of chemical equilibria in solutions under pressure will be presented in order to give a characteristic example.

In Fig. 18 the spectrum of an aqueous solution containing nickel and murexide ions is plotted at 1, 500,1000 and 1500 bar according to measurements of Jost. ${ }^{108}$ An isosbestic point is observed by application of pressure only; the peak at $460 \mathrm{~nm}$ corresponds to the nickel-murexide complex.

From the spectrum in Fig. 18 the equilibrium constant $K$ has been calculated ${ }^{108}$ as a function of pressure according to well-known techniques. In Fig. 19 the logarithm of the equilibrium constant $K$ thus obtained is plotted against the pressure in bar. Within the limits of experimental error a straight line results; from the slope the standard value of the reaction volume $\Delta V^{\theta}$ has been calculated by $\mathrm{Jost}^{108}$ to be $22.6 \mathrm{~cm}^{3} \cdot \mathrm{mol}^{-1}$ using the well-known thermodynamic relation (19)

$$
\Delta V^{\theta}=-R T\left(\frac{\partial \ln K}{\partial p}\right) T
$$

These measurements have been carried out with a high

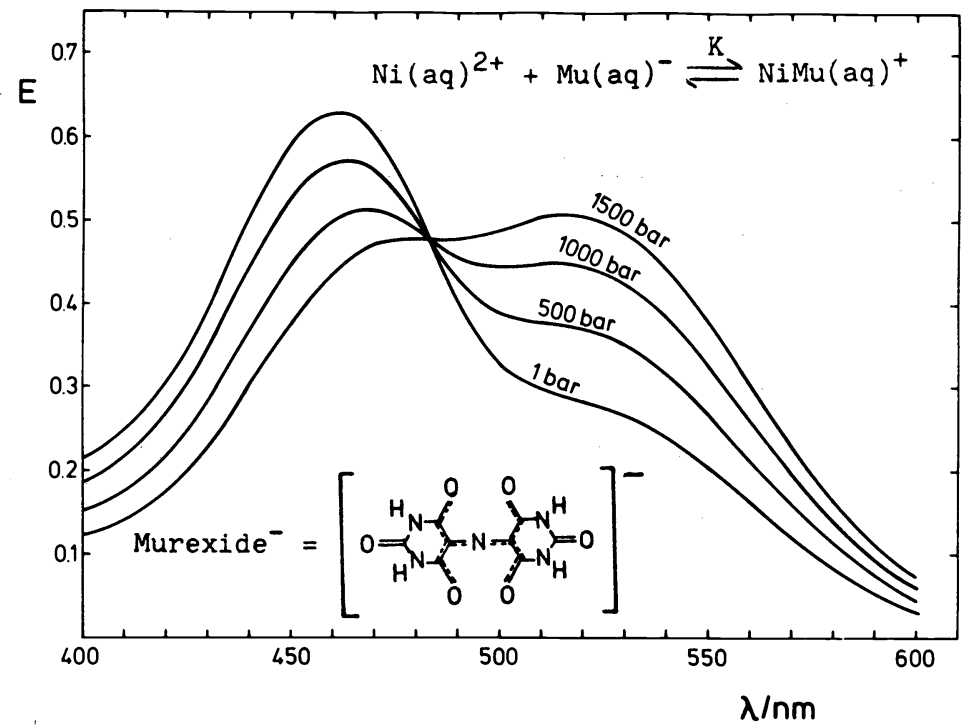

Fig. 18. Spectrum of the system $\mathrm{Ni}^{2+}+$ murexide $-/$ water at $25^{\circ} \mathrm{C}$ and at different pressures (according to results of Jost $^{108} ; c_{0}\left(\mathrm{Ni}^{2+}\right)=8.0 \times 10^{-4} \mathrm{~mol} \mathrm{dm}^{-3} ; c_{0}\left(\mathrm{Mu}^{-}\right)=5.66 \times 10^{-5} \mathrm{~mol} \mathrm{dm}^{-3} ; I=0.1 \mathrm{~mol} \mathrm{dm}^{-3}\left(\mathrm{NaClO}_{4}\right.$; ionic strength); $\mathrm{pH}=5.0$ ). 


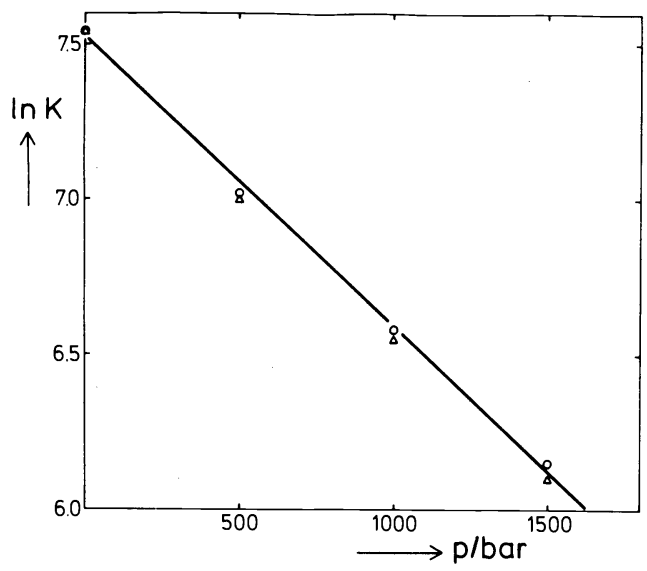

Fig. 19. Pressure dependence of the overall equilibrium constant $K$ for the system $\mathrm{Ni}^{2+}+$ murexide $-/$ water at $25^{\circ} \mathrm{C}$ (according to results of $\mathrm{Jost}^{108} ; K$ in $\mathrm{mol} \mathrm{dm}^{-3}$ ).

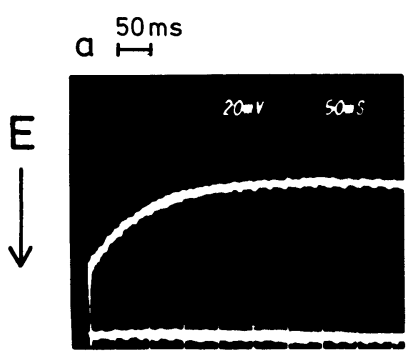

1 bar b $50 \mathrm{~ms}$

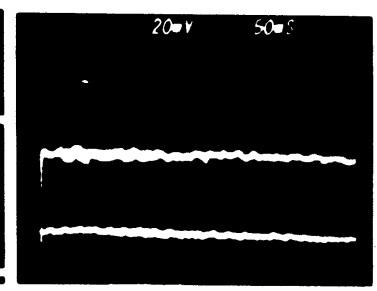

560 bar

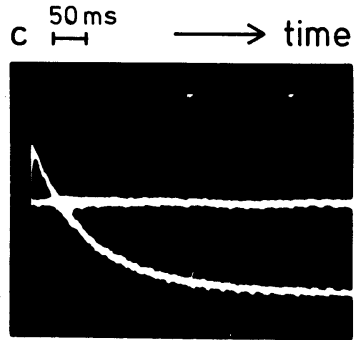

1600 bar

$\triangle \mathrm{H}<0$

$\triangle \mathrm{H}>0$

Fig. 20. Temperature-jump relaxation traces at 1,560 and 1600 bar for the system $\mathrm{Ni}^{2+}+$ murexide ${ }^{-}$/water (according to results of Jost ${ }^{108} ; \Delta T=8.0^{\circ} \mathrm{K} ; T($ final $)=298.15^{\circ} \mathrm{K} ; \lambda=460 \mathrm{~nm} ; c_{0}\left(\mathrm{Ni}^{2+}\right)=8.0 \times 10^{-4} \mathrm{~mol} \mathrm{dm}^{-3} ; c_{0}\left(\mathrm{Mu}^{-}\right)=$ $5.4 \times 10^{-5} \mathrm{~mol} \mathrm{dm}^{-3} ; I=0.1 \mathrm{~mol} \mathrm{dm}{ }^{-3}\left(\mathrm{NaClO}_{4} ;\right.$ ionic strength $\left.)\right)$.

pressure optical cell in a commercial spectrometer; they were made in connection with kinetic investigations of very fast reactions in solution at high pressure using the temperature jump relaxation technique and will be published elsewhere ${ }^{49,108} \mathrm{~A}$ result that is interesting from a thermodynamic point of view, however, is shown in Fig. 20. Here the traces on the screen of an oscilloscope showing the optical extinction of the solution as a function of time after a temperature jump are represented at 1, 560 and 1600 bar. Whereas the optical extinction and consequently the complex concentration decreases with time after the temperature jump at 1 bar, it remains practically unchanged by the temperature jump at 560 bar and on the contrary increases at 1600 bar. The consequence is that the reaction enthalpy $\Delta H^{\theta}$ must change its sign from minus to plus with increasing pressure at constant temperature in this system; this is a very remarkable pressure effect for a reaction in liquid solution, where often pressure effects are widely neglected. From the relaxation curves in Fig. 20 approximate values of $\Delta H^{\theta}$ can be calculated. ${ }^{108}$

It was the aim of this lecture to stimulate the interest in the thermodynamic properties of mixtures at high pressures which really merit to be investigated to a greater extent in the future.

Acknowledgements-The author thanks the Deutsche Forschungsgemeinschaft and the Verband der Chemischen Industrie e.V. for supporting the experiments cited that have been performed in the author's group at the University of Bochum, German Federal Republic.

\section{REFERENCES}

${ }^{1}$ L. Merrill, Bibliography on High Pressure Research. Brigham Young University, Provo, Utah, USA.

${ }^{2}$ E. Kuss, Fortschr. Verfahrenstech. 9, 32 (1968/69).

${ }^{3}$ E. U. Franck, Plenary lecture presented at the 3rd Int. Conf. on Chemical Thermodynamics, 3-7 September, 1973, Baden, Vienna, Austria. Pure Appl. Chem. 38, 449 (1974).

${ }^{4} \mathrm{~S}$. D. Hamann, in Modern Aspects of Electrochemistry (editors J. O'M. Bockris and B. E. Conway), Vol. 9, Chap. 2. Plenum, New York (1974).

${ }^{5}$ V. Pilz, Verfahrenstech. 9, 280 (1975).

${ }^{6} \mathrm{R}$. Haase, Thermodynamik der Mischphasen. Springer, Berlin (1956).

${ }^{7}$ J. S. Rowlinson, Liquids and Liquid Mixtures. 2nd Edn, Butterworth, London (1969).

${ }^{8} \mathrm{~J}$. M. Prausnitz, Molecular Thermodynamics of Fluid Phase Equilibria. Prentice Hall, Englewood Cliffs (1969).

${ }^{9} \mathrm{P}$. G. Tait, Physics and Chemistry of the Voyage of H.M.S. Challenger. Vol. 2, Part 4 (1888); G. Tammann, Über die Beziehungen zwischen den inneren Kräften und Eigenschaften der Lösungen, Hamburg (1907).

${ }^{10}$ C. J. Hudleston, Trans. Faraday Soc. 33, 97 (1937).

${ }^{11}$ A. T. J. Hayward, Brit. J. Appl. Phys. 18, 965 (1967).

${ }^{12}$ P. M. Chaudhuri, Can. J. Chem. Eng. 46, 132 (1968).

${ }^{13} \mathrm{~K}$. Witt, Antriebstech. 12, 137 (1973).

${ }^{14} \mathrm{~F}$. Hötte, Chem. Ingr-Tech. 46, 762 (1974).

${ }^{15}$ E. Kuss, Chem. Ingr-Tech. 46, 750 (1974).

${ }^{16}$ B. Battino, Chem. Rev. 71, 5 (1971).

${ }^{17}$ S. D. Hamann and F. Smyth, Aust. J. Chem. 24, 2431 (1971). ${ }^{18}$ P. Engels, Ph.D. thesis, University of Karlsruhe, GFR (1970).

${ }^{19}$ P. Engels and G. M. Schneider, Ber. Bunsenges. phys. Chemie, 74, 931 (1970).

${ }^{20}$ P. Engels, G. Götze and G. M. Schneider, Paper presented at the 
3rd Int. Conf. Chemical Thermodynamics, 3-7 September, 1973, Baden, Austria; section V/21.

${ }^{21}$ J. A. Lamb and A. F. Hunt, Chem. Engng J. To be published.

${ }^{22}$ J. Korpela, Acta Chem. Scand. 25, 2852 (1971).

${ }^{23} \mathrm{G}$. Götze, Diplom thesis, University of Bochum GFR (1972); G. Götze, P. Engels and G. M. Schneider, Chem. Ingr-Tech. 46, 750 (1974).

${ }^{24} \mathrm{G}$. Götze, Ph.D. thesis, University of Bochum, GFR, In preparation.

${ }^{25}$ G. Götze, R. Jockers and G. M. Schneider, Paper presented at the 4th Int. Conf. Chemical Thermodynamics, 26-30 August, 1975, Montpellier, France; section IV/9.

${ }^{26} \mathrm{H}$. Lentz, paper presented at the Ulmer Kalorimetrietage, 3-4 April, 1975, Ulm, GFR.

${ }^{27}$ D. S. Tsiklis, Phasentrennung in Gasgemischen, VEB Deutscher Verlag für Grundstoffindustrie, Leipzig (1972).

${ }^{28} \mathrm{D}$. S. Tsiklis and L. A. Rott, Russ. Chem. Rev. 36, 351 (1967).

${ }^{29}$ G. M. Schneider, Ber. Bunsenges. phys. Chemie 70, 497 (1966).

${ }^{30}$ G. M. Schneider, Fortschr. Chem. Forsch. 13, 559 (1970).

${ }^{31}$ G. M. Schneider, Advan. Chem. Phy. 17, 1 (1970).

${ }^{32}$ G. M. Schneider, Ber. Bunsenges. phys. Chemie 76, 325 (1972).

${ }^{33}$ G. M. Schneider, in: Chemical Thermodynamics. Vol. 2, Chemical Society Specialist Reports. To be published.

${ }^{34} \mathrm{G}$. M. Schneider in Water-A Comprehensive Treatise. (editor F. Franks), Vol. 2, Chap. 6, Plenum, New York (1973).

${ }^{35}$ R. L. Scott, Ber. Bunsenges. phys. Chemie 76, 296 (1972); R. L. Scott, paper presented at the 3 rd Int. Conf. Chemical Thermodynamics, 3-7 September, 1973, Vienna, Austria, section IV/11a.

${ }^{36}$ D. S. Tsiklis, Handbook of Techniques in High-Pressure Research and Engineering. Plenum, New York (1968).

${ }^{37}$ I. Prigogine and R. Defay, Chemical Thermodynamics. Longmans, Green, London (1954); I. Prigogine and R. Defay, Chemische Thermodynamik, VEB Deutscher Verlag für Grundstoffindustrie, Leipzig (1962).

${ }^{38}$ I. M. Croll and R. L. Scott, J. Phys. Chem. 62, 954 (1968).

${ }^{39}$ J. H. Hildebrand, J. M. Prausnitz and R. L. Scott, Regular and Related Solutions, Van Nostrand, New York (1970).

${ }^{40} \mathrm{R}$. Paas, Ph.D. thesis, University of Bochum, GFR, In preparation.

${ }^{41}$ G. D. Efremova and A. V. Shvarts, Russ. J. Phys. Chem. 46, 237 (1972); R. B. Griffiths, Physica 73, 174 (1974).

${ }^{42}$ K. Peter, Ph.D. thesis, University of Bochum, GFR (1974).

${ }^{43} \mathrm{~K}$. Peter and G. M. Schneider, Paper presented at the $3 \mathrm{rd}$ Int. Conf. Chemical Thermodynamics, 3-7 September, 1973, Baden, Austria, section IV/10; K. Peter and G. M. Schneider, Ber. Bunsenges. phys. Chemie 77, 1013 (1973).

${ }^{44} \mathrm{R}$. Paas, Diplom thesis, University of Bochum, GFR (1974); J. Chem. Thermodyn., To be published.

${ }^{45}$ G. M. Schneider and C. Russo, Ber. Bunsenges. phys. Chemie 70, 1008 (1966).

${ }^{46}$ J. P. Novak and G. M. Schneider, Ber. Bunsenges. phys. Chemie 72, 791 (1968).

${ }^{47}$ A. Jost and G. M. Schneider, J. Phys. Chem. 79, 858 (1975).

${ }^{48}$ U. Limbach, Diplom thesis, University of Bochum, GFR (1975).

${ }^{49}$ A. Jost, Ber. Bunsenges. phys. Chemie 78, 300 (1974).

${ }^{50}$ J. Zernike, Chemical Phase Theory. Kluwer, Deventer Djakarta (1955).

${ }^{51}$ J. D. van der Waals, Zittingsversl. Koninkl. Akad. Wetenschap. Proc. Ser. B133 (1894); (see also J. de Boer, Physica 73, 1 (1974)).

${ }^{52}$ H. Kamerlingh Onnes and W. H. Keesom, Comm. Phys. Lab. Univ. Leiden, Suppl. No. 15 (1907); Koninkl. Ned. Akad. Wetenschap. Proc. Ser. B9, 786 (1907), 10, 231 (1907).

${ }^{53}$ I. R. Krichevskii, Acta Phys. Chim. USSR 12, 480 (1940); I. R. Krichevskii and P. E. Bol'shakov, Zh. Fiz. Khim. 15, 184 (1941); I. R. Krichevskii and D. S. Tsiklis Zh. Fiz. Khim. 15, 1059 (1941), 17, 126 (1943); D. S. Tsiklis, Dokl. Akad. Nauk SSSR 86, 993 (1952).

${ }^{54}$ D. S. Tsiklis, Dokl. Akad. Nauk SSSR 86, 1159 (1952).

${ }^{55}$ W. B. Streett, Trans. Faraday Soc. 65, 696 (1969).

${ }^{56}$ W. B. Streett, Astrophys. J. 186, 1107 (1973).

${ }^{57}$ W. B. Streett, Chem. Eng. Progr. Symp. Ser. 81, 63, 37 (1967).
${ }^{58}$ W. B. Streett and J. L. E. Hill, Trans. Faraday Soc. 67, 622 (1971).

${ }^{59}$ C. K. Heck and P. L. Barrick, Advan. Cryog. Eng. 12,714 (1967).

${ }^{60}$ W. B. Streett, A. L. Erickson and J. L. E. Hill, Phys. Earth Planet. Interiors 6, 69 (1972).

${ }^{61}$ J. de Swaan Arons and G. A. M. Diepen, J. Chem. Phys. 44, 2322 (1966).

${ }^{62}$ D. S. Tsiklis, Dokl. Akad. Nauk SSSR 86, 1159 (1952).

${ }^{63}$ N. J. Trappeniers and J. A. Schouten, Physica 73, 546 (1974).

${ }^{64}$ W. B. Streett, Can. J. Chem. Eng. 52, 92 (1974).

${ }^{65}$ Z. Alwani, University of Bochum, GFR, Unpublished results.

${ }^{66}$ G. M. Schneider, Z. Alwani, W. Heim, E. Horvath and E. U. Franck, Chem. Ingr-Tech. 39, 649 (1967).

${ }^{67}$ K. G. Liphard and G. M. Schneider, J. Chem. Therm. 7 (1975), in press.

${ }^{68} \mathrm{~K}$. Tödheide and E. U. Franck, Z. Physik. Chem (Frankfurt) 37, 387 (1963).

${ }^{69} \mathrm{~K}$. Zosel, Offenlegungsschrift 1,493,190, Deutsches Patentamt München; O. Vitzhum et al., Patentschrift 2,127, 618, Deutsches Patentamt München. T. P. Zhuze and M. A. Kapelyushnikov, USSR patent No. 113,325 (1958); H. V. Hess et al., US patent No $3,318,805$ (1967).

${ }^{70}$ T. H. Gouw and R. E. Jentoft, J. Chromatog. 68, 203 (1972); Advan. Chromatog., in press.

${ }^{71}$ M. N. Myers and J. C. Giddings, Progr. Separ. Purif. 3, 133 (1970).

${ }^{72}$ D. Bartmann, Ber. Bunsenges. phys. Chemie 76, 336 (1972)

${ }^{73}$ D. Bartmann and G. M. Schneider, J. Chromatog. 83, 135 (1973).

${ }^{74}$ U. van Wasen and G. M. Schneider, Chromatographia 8, 274 (1975).

${ }^{75}$ G. M. Schneider, Experimental Thermodynamics. (editors B. Le Neindre and B. Vodar), Vol. 2, Chap. 16, part 2. Butterworth, London (1975).

${ }^{76}$ G. M. Schneider, Z. Physik. Chem. (Frankfurt) 46, 375 (1965).

${ }^{77}$ D. Oeder and G. M. Schneider, Ber. Bunsenges. phys. Chemie 73, 229 (1969); 74, 580 (1970).

${ }^{78}$ I. R. Krichevskii and D. S. Tsiklis, Zh. Fiz. Khim. 17, 126 (1943).

${ }^{79}$ A. J. Davenport, J. S. Rowlinson and G. Saville, Trans. Faraday Soc. 62, 322 (1966).

${ }^{80}$ R. L. Scott and P. H. van Konynenburg, Dis. Faraday Soc. 49, 87 (1970); P. H. van Konynenburg, Ph.D. thesis, UCLA (1968).

${ }^{81}$ B. A. Wolf and G. Blaum, paper presented at the 4th Int. Conf. Chemical Thermodynamics, 26-30 August, 1975, Montpellier, France, section IV/8.

${ }^{82} \mathrm{E}$. Horvath, Diplom thesis, University of Karlsruhe, GFR (1965).

${ }^{83}$ W. W. Akers, J. F. Burns and W. R. Fairchild, Ind. Eng. Chem. 46, 2531 (1954).

${ }^{84}$ H. H. Reamer and B. H. Sage, J. Chem. Engng Data 7, 161 (1962); H. H. Reamer and V. Berry, J. Chem. Engng Data 7, 486 (1962).

${ }^{85}$ P. Ehrlich, J. Polym. Sci., A3, 131 (1965).

${ }^{86}$ R. Steiner and K. Horlé, Chem. Ingr-Tech. 44, 1010 (1972).

${ }^{87}$ J. S. Rowlinson, Plenary lecture presented at the 3 rd Int. Conf. Chemical Thermodynamics, 3-7 September, 1973, Baden, Austria; Pure Appl. Chem. 38, 495 (1975).

${ }^{88}$ G. M. Wilson, Advan. Cryog. Eng. 9, 168 (1964).

${ }^{89}$ J. M. Prausnitz and P. L. Chueh, Computer Calculations for High-Pressure Vapor-Liquid Equilibria. Prentice Hall, Englewood Cliffs (1968).

${ }^{90}$ D. Zudkevitch and J. Joffe, A.I.Ch.E. J. 16, 112 (1970).

${ }^{91}$ J. Joffe, G. M. Schroeder and D. Zudkevitch, A.I.Ch.E. J. 16, 469 (1970).

${ }^{92}$ S. Peter and H. Wenzel, Chem. Ingr-Tech. 43, 623 (1971).

${ }^{93} \mathrm{H}$. Wenzel and S. Peter, Chem. Ingr-Tech. 43, 856 (1971).

${ }^{94}$ S. Peter, G. Brunner and R. Riha, Dechema Monograph, 73, 197 (1974).

${ }^{95}$ S. Peter, G. Brunner and R. Riha, Chem. Ingr-Tech. 46, 623 (1974).

${ }^{96}$ G. J. F. Breedveld and J. M. Prausnitz, A.I.Ch.E. J. 19, 783 (1973).

${ }^{97}$ H. Renon, J. Chandron and L. Asselineau, Paper presented at the CHISA congress, Prague (1972). 
${ }^{98}$ P. Zandbergen, H. F. P. Knaap and J. J. M. Beenakker, Physica 33, 379 (1967).

${ }^{99}$ P. Y. Tan, K. D. Luks and J. J. Kozak, J. Chem. Phys. 55, 1012 (1971).

${ }^{100}$ M. Rigby, B. J. Alder, A. M. Sapse and C. E. Hecht, J. Chem. Phys. 52, 3665 (1970).

${ }^{101}$ N. J. Trappeniers, J. A. Schouten and C. A. Ten Seldam, Chem. Phys. Lett. 5, 541 (1970).

${ }^{102}$ J. A. Schouten, C. A. Ten Seldam and and N. T. Trappeniers, Physica 73, 556 (1974).

${ }^{103}$ G. W. Mulholland and J. J. Rehr, J. Chem. Phys. 60, 1297 (1974).

${ }^{104}$ R. O. Neff and D. A. McQuarrie, J. Phys. Chem. 79, 1022 (1975).

${ }^{105}$ J. T. Bartis and C. K. Hall, Cornell University, Ithaca, N.Y., To be published.

${ }^{106}$ U. Deiters, Diplom thesis, University of Bochum (1975).

${ }^{107}$ B. H. Sage and W. N. Lacey, Thermodynamic Properties of the
Lighter Paraffin Hydrocarbons and Nitrogen. American Petrochemical Institute, New York (1950).

${ }^{108}$ A. Jost, Ber. Bunsenges. phys. Chemie 79, 850 (1975).

${ }^{109}$ M. Elborai, Ph.D. thesis, University of Karlsruhe, GFR (1974).

${ }^{110} \mathrm{~J}$. Timmermans, The Physico-chemical Constants of Binary Systems in Concentrated Solutions. Vol. 1-4, Interscience, New York (1960).

${ }^{111}$ Landolt-Börnstein, Numerical Data and Functional Relationships in Science and Technology. New Series, Group IV, Vol. 1, Densities of liquid systems, Part a, Springer, New York (1974).

${ }^{112}$ M. L. McGlashan, K. Stead and C. Warr, paper presented at the 3rd Int. Conf. Chemical Thermodynamics, 3-7 September, 1973, Baden, Austria; section IV/11b.

${ }^{113}$ A. L. Horvath, Chem. Ingr-Tech. 47, 859 (1975).

${ }^{114}$ D. S. Tsiklis et al., Zh. Fiz. Khim. 48, 217 (1974). 